Paul W. Thurner, André Klima \& Helmut Küchenhoff

\title{
Agricultural Structure and the Rise of the Nazi Party Reconsidered
}

Technical Report Number 162, 2014

Department of Statistics

University of Munich

http://www.stat.uni-muenchen.de 


\title{
Agricultural Structure and the Rise of the Nazi Party Reconsidered
}

\author{
Paul W. Thurner ${ }^{*}$, André Klima ${ }^{\dagger}$, Helmut Küchenhoff ${ }^{\dagger}$ \\ * Department of Political Science, Ludwig-Maximilians-Universität Munich, Germany \\ ${ }^{\dagger}$ Department of Statistics, Ludwig-Maximilians-Universitat Munich, Germany
}

\author{
Corresponding Author \\ Paul W. Thurner \\ Department of Political Science \\ Chair for Empirical Political Research and Policy Analysis \\ Ludwig-Maximilians-Universität Munich, Germany \\ Oettingenstr. 67, 80538 München \\ Tel.: + $49(0) 89$ / 21809081 \\ Fax: +49 (0) 89 / 21809092 \\ Email: paul.thurner@gsi.uni-muenchen.de
}

\begin{abstract}
There is widespread agreement within academic literature that the NSDAP systematically and effectively targeted the rural areas beginning with the agrarian crisis in 1927/8. However, one issue is left unresolved: were specific levels of agricultural strata differently attracted to the Nazis, and if so, how? In light of the economic and political incentives offered to German peasants with differing farm sizes, we expect that regions characterized by middle peasants were most likely to have electorally swung in a distinct, asymmetric and relevant way towards the Nazis. In order to test this hypothesis, we have used a country-wide data set, which includes the original categories of 'parcel peasants' (0-2 hectare), 'small-sized' (2-5 hectare) and 'medium-sized' farmers (5-20 hectare). These specific classifications were introduced and behaviorally legitimated by the Statistical Office of the Weimar Republic at that time. We present the first analysis applying generalised additive models (GAM) for the assessment of ecological relations. In order to account for the construction of political spaces - and therefore of spatial dependencies, we offer a new mechanism based on stipulations of the electoral system. Even after controlling for pre-established impact factors (protestantism, urbanization, etc.) and for spatial effects, we identify a clear impact of the agrarian middle classes (5-20 hectare) on the Nazi vote beginning with the election in July 1932.
\end{abstract}


The established scientific consensus is that by the end of the 1920s the Nazi party achieved a major electoral breakthrough in the rural parts of the Weimar Republic (see Heberle 1934/1963, 1945 Friedrich 1937, Waldman 1973, Falter 1991, Brustein 1996): “compared to the urban population, rural voters initially moved only slowly to the Nazis, from 1928 to 1930. They then moved much more rapidly to the Nazis from 1930 to 1933" (Shively 1972: 1213). Peasant parties, some of them newly created in the course of the Agrarian Crisis, attracted 1.37 million votes in 1928 and reached their peak with 1.62 million votes in 1930 . Comparing their results in 1930 with the one in the final democratic election in 1933, it turns out that they lost 1.18 million votes. Compared with the 17 million voters for the NSDAP in March 1933, this would account for about 6.8 percent. ${ }^{1}$ In short: in 1932, "the NSDAP had now clearly established as the most important peasant party” (Corni 1990: 32). Thus, the gains in the countryside were an important contribution to the seizure of power.

Surprisingly, it remains unclear whether agricultural strata played a differential role in the electoral dynamics of the Nazi party, i.e.: Did agricultural strata have an impact? If so, which agricultural strata had an impact? Early research on the electoral breakthrough of the Nazi party asserted that administrative units (Kreise, in the following: counties) characterized by small- and middle-sized farms voted in large numbers for the NSDAP (see Heberle (1934/1963, 1945) and Loomis/Beegle (1946)). In his famous analysis of Fascism as a specific type of middle class extremism, Lipset (1960: 140-149) considered both the old and new middle class as having been susceptible to the NSDAP propaganda. Later studies, however, denied the exclusive attraction of the middle class, and instead emphasized the fact that the Nazis succeeded in making inroads into to other classes and segments of the population (see Falter 1986, Falter 1991: 256-265). More specifically, Falter rejected the rural middle class hypothesis. He argued that it was restricted to pecularities of the regions investigated by Heberle and Loomis/Beegle and, therefore not generalizable to the whole Reich. The main results of his research are: a) the rural breakthrough of the NSDAP in a national sense only became visible in the July 1932 election; b) this relationship was much stronger, or even only exclusively related to protestant regions; and c) there was definitely no effect of specific rural strata, either in protestant, or in catholic regions. Due to their heterogeneous social foundations, the Nazis were called the "First German Volkspartei" (Falter 1990). Despite the broad social appeal of the NSDAP being undeniable, some authors nevertheless continue to seek segment-specific appeal as well as regional variations in support (see O’Loughlin 1994, 2002, Brustein 1996, King et al. 2008). Due to the disastrous consequences of their electoral success it is still of enormous interest to fully understand how this party was able to form the political landscape (see Flint 1998, 2001) and which specific economic interests it appealed in a distinguishable and asymmetric way (King et al. 2008,

1

Note that this constitutes a very ,conservative“ estimate. Including peasantry-related losses of, e.g., the Economics Party (Wirtschaftspartei) or the Conservative and Liberal Parties, the value would be very much higher. 
Brustein 1996). Studies focusing on the spatial distribution of the Nazi vote found regional variations and hot spots indicating differential local and regional campaign effectiveness (see Flint 1998, 2001, O’Loughlin et al., 1994, O’Loughlin 2002).

Studies taking an economic and incentive-oriented view provide evidence that it was the owners of small and medium-sized businesses who were attracted by the Nazi propaganda (King et al. 2008). This stratum was characterized by its fierce opposition to socialism and to large companies and rural estates. Brustein (1996: 63-109) delineates in detail the match between the material interests of these segments and the respective policy offered by some of the parties: small and mid-sized farmers were asymmetrically and distinctly hit by the agrarian crisis, i.e. by the decrease of agricultural prices, and of credit availability, and by bankruptcy. The pre-crisis party affiliations of this specific segment tended towards the liberal parties such as the DDP and DVP, as well as towards the conservative party DNVP, and towards the catholic Center Party. These affiliations began to weaken in 1927 - due to the inconsistent position-taking and policy-making of these parties with regard to protective agricultural tariffs and subsidies. The peasants' attempt to organize agricultural movements and to establish new parties proved to be only partially successful during 1928. It was the distinctive change in programme of the NSDAP, together with their systematic infiltration of existing farmers' organizations which led to a large-scale absorption of small and mid-sized farms into the voters for the NSDAP, already visible with the election in 1930.

Actually, the size of farms constitutes the fundamental factor of rural stratification. After the abolishment of feudal corporations in Europe, farm size determined to a large degree the social and economic status of peasants. Soil pecularities and the specialization with regard to agrarian products (livestock breeding versus cultivation of grains) may also have formed the material interests and income of peasants. But, it is the size of farms which provides a reliable proxy, and which reflects the incidence of very unbalanced agricultural policy-making in the Weimar Republic. ${ }^{2}$ Therefore, the respective statistical classification is essential in determining socially and politically relevant rural strata. The Office of Statistics of the Weimar Republic distinguished the following categories: ${ }^{3}$

Table 1: Categories of Farm Size

\begin{tabular}{|l|l|}
\hline Farms size (hectare: ha $=10000 \mathrm{~m}^{2}$ ) & Category \\
\hline $0-2$ ha & Parcel farms \\
\hline $2-5$ ha & Small farms \\
\hline $5-20$ ha & Medium-sized farms \\
\hline $20-100$ ha & Large farms \\
\hline 100 ha and more & Large estates \\
\hline
\end{tabular}

2 For details see Brustein (1996: $64 \mathrm{ff})$

3 See Statistik des Deutschen Reichs (1929). 
In their early studies of the Nazi vote, Heberle (1934/1945) and Loomis/Beegle (1946) closely followed the reasoning of the Official Statistics of the Reich. They expected small farms (2-5 ha) and medium-sized (5-20 ha) to be the politically most relevant strata with the highest likelihood to vote for the Nazi party. Heberle (1934/1963, 1945). Loomis/Beegle (1946) corroborated their hypotheses empirically - but only within specific, sometimes highly aggregated regions. Later, Waldman (1973) operationalized farm sizes 2-100 ha ${ }^{4}$ as so-called family farms and, therefore, as more politically relevant in regard to Nazi voting. ${ }^{5}$ Falter (1986, 1991), was the first researcher to use a fine-grained country-wide data set. In his analyses, he combined the categories of parcel peasants (0-2 ha), small farms (2-5 ha) and medium-sized (5-20 ha) farms into one single category which he labeled "medium-sized farms" (0-20 ha). Additionally, he also proposed a measure of a so-called "average farm size" $^{\prime 6}$ as an indicator of medium-sized farms. Third, he used the indicator of the share of family workers as a complementary indicator for medium-sized farms. The respective correlations -shown in more detail below - are indeed small or non-existent, sometimes even negative. In summary, results relating to the (non-)impact of farm sizes, are in our view still inconclusive - theoretically as well as methodically.

Thus, more than 80 years after the destruction of the Weimar Republic, there remains a surprising puzzle: Was the rural Nazi vote, at least beginning with the election in 1930, indeed a phenomenon related to radicalized small and midsize farmers - as argued by Geiger (1932), Heberle (1934/1963, 1945), Loomis/Beegle (1946), Lipset (1960), Linz (1976) and Brustein (1996)? Or was there an identical electoral appeal of the Nazis across all agrarian societal strata -as suggested by Falter? Considering the results of Gessner (1981) and Brustein (1996), we argue that the complex interplay between the specific economic interests of mid-sized farms in the German Reich, and of the dynamics of the agrarian political interest mediation after the Agrarian Crisis in 1927/28 led finally to the dramatic erosion of newly founded peasant parties, and to the absorption of their adherents by the Nazis. ${ }^{7}$ In a highly strategic way, Hitler reacted programmatically to these developments and used the NSDAP's party machine to create favourable political spaces (see Flint 1998, 2001) in the countryside. For the first time, we propose to identify political spaces along those institutions being relevant for 'making votes count' (Cox 1997), i.e. along electoral districts, see Table 6 in the appendix.

In order to test these hypotheses, we will use a new data set. This is the first country-wide study using the original classification of parcel peasants (0-2 ha), small-sized (2-5 ha) and medium-sized farmers (5-20 ha) from the Weimar Republic- i.e.: as introduced by the Office of Statistics of the Weimar Republic, and used by the classic regional study by Heberle

4 Waldman (1973):181, FN.: 3, see also Table 43 on p. 198 where he actually correlates 2-20 ha and 20-100 ha with the Nazi vote, respectively.

5 Actually, this operationalization of Waldman is problematic, as all farms with 10-20 ha employed permanent wage workers. Even in the category of 5-10 ha, $40 \%$ of the farms employed permanent wage workers. See Jatzlauk 1986: 27 based on Statistik des Deutschen Reichs. More generally, this shows also that the frequent equation: , family farms $=$ middle class farms' ${ }^{6}$ is wrong.

6 I.e., the mean value of farm sizes in a county.

7 For this hypothesis of a collapse of the agrarian system of political interest mediation, see Wehler 2008: 339, Gessner 1981, Jones 1986. 
(1934/1963, 1945). Additionally, we will for the first time control for electoral districts and institutionally stipulated associations of such districts.

In the following, we will first provide a short overview of the literature detailing the agricultural crisis in the Weimar Republic. Then, we will briefly review the quantitative literature about the relationship between agricultural structure and the Nazi vote. Based on these insights, we will propose new hypotheses with regard to the rural basis of the Nazis. We will also suggest a new theoretical rationale for its systematic geographic variation. We will test our hypotheses for the first time using the fine-grained original classification of the Official Statistics. We will introduce data and present a new statistical approach to the study of the Nazi party called generalized additive models (see Keele 2008). Finally, we discuss our empirical results, which indicate the clear middle class basis of the rural Nazi vote since the 1932 elections.

\section{Agricultural Crisis and Political Interest Representation of Peasants in the Weimar Republic}

The importance of the peasantry in the rise of the Nazis was recognized very early (Heberle 1934/1963, 1945, Friedrich 1937, Loomis/Beegle 1946). As a consequence, the literature on the specific rural component in the failure of the first German Republic is extensive. There are numerous publications on agricultural policy and on agrarian interest groups by, e.g. Gessner (1981), Jones (1986), Brustein (1986), Corni (1990).

Seen from the perspective of economic history ${ }^{8}$, the political role of the agricultural sector in the Weimar Republic has been surprisingly disproportionate - as compared to its contribution to economic production, namely approx. $16 \%$ of domestic net product in the years 1925-1929 (James 1986: 242). In 1925, approx. 30\% (i.e. ca. 9.7 million people) of the workforce was still constituted by this sector - which sheds light on its low productivity as compared to the industrial sector. Within this sector, the social stratification of the peasantry was highly differentiated. ${ }^{9}$ In sum, more than 2 million peasants earned their living from their agricultural business. Only $1 \%(\mathrm{~N}=23000)$ of the landowners had very large land estates (larger than 100 ha). Peasants owning large quantities of land consisting of 50-100 ha and socalled full farmers owning 20-50 ha land estates represented $13 \%$ (ca. $\mathrm{N}=262000$ ). According to the 1925 census, there were 1006094 farms of size 5-20 ha, with 919687 run by full time middle peasants. These mid-sized farms relied on 2162079 permanently employed family members and 577802 full time land workers. The occurrence of this type of farms was evenly distributed across the Reich - with core areas in Wuerttemberg, Bavaria, Saxony, Westphalia, Schleswig-Holstein etc. (see Jatzlauk 1986, Brustein 1996). It is important to note, that most farms with10-20 ha in size relied on permanently employed land workers as compared to only $40 \%$ of farms with 5-10 ha. Thus, the equation: middle farmers

8 Useful historical overviews are provided, e.g., by James (1986.

9 For the following, see the social history-oriented resume by Wehler (2008): 331ff, see also Geiger (1932): 30-34, Gessner 1981, Jatzlauk 1986. 
= family farms is not appropriate. Additionally, more than 3 million so-called parcel peasants owned 0-2 ha - and they were considered as agricultural 'proletarians', e.g. by sociologists like Geiger (1932/1967: 33) Whereas large estate owners, large peasants and full peasants were able to earn their living from their properties, land owning was not the exclusive source of livelihood for parcel peasants. They had to rely on an additional occupation, e.g. serving as a land laborer, which was perceived as a clear degradation in the rural status hierarchy. Owners with mid-sized farms constituted a segment of the peasantry with distinct material interests. Their material interests were distinct from other peasants because German agricultural interest mediation and policy-making was under the control of large tenants, e.g. tariff policies reflected the political power of very large land owners in Eastern Germany. World market prices for wheat began to decline in 1925 and in 1926/27, a global crisis of agriculture compelled German farmers to take out loans in order to compensate for price reduction and price controls as well as for an increase of taxes. From 1928 to 1932, German governments followed a highly protective tariff policy in order to secure wheat prices agrarian protectionism became the "sacrosanct custom" (Wehler 2008: 314). However, these interventions did not have identical repercussions across the peasantry - due to its highly heterogeneous social and economic structure, most specifically with regard to farm sizes but also with regard to product specialization (grains versus cattle). Protective tariff measures were beneficial mainly for large owners in Eastern Germany producing wheat.

This heterogeneity of peasant's economic interests impeded a national and unified interest formation which could be represented by the established parties (see Gessner 1981, Jones 1986, Brustein 1996). The only peasant party represented in the German parliament (Reichstag) until 1928 was the Bavarian Peasants' Asscociation (Bayerischer Bauernbund). Liberal parties (DDP, DVP), the Economics Party (Wirtschaftspartei), as well as Catholic (Zentrum, BVP) and Protestant Conservative Parties (DNVP) hosted candidates of the peasants' main interest organization, the Association of Peasants (Bund der Landwirte) on their party lists from 1920 to 1928. Inherent organizational tensions between small and medium-sized farmers on the one hand, and large farmers on the other, intensified during the aggravation of the Agrarian Crisis by the end of the 1920s (see Jones 1986). Peasant movements spread, and contributed to the formation of new peasant parties, e.g. in 1927 the formation of the German Peasant Party (DBP), and the Christian-National Peasant Party (Christlich-Nationale Bauern- und Landvolk-Partei (CNBP)) in 1928 - a split off from the DVP and the DNVP. In retrospect, these new parties proved to be "flash parties" (Rose/Mackie, 1988) or "intermediate hosts". They mainly attracted the Protestant peasant clientele of the conservative and liberal parties in the 1928 election and in the 1930 election but their electorate was by then almost completely decimated in the 1932-1933 elections. Peasant parties in Catholic regions, like in Bavaria the Bayerische Bauernbund (BBB), experienced a similar decline but to a slightly less extensive degree. In 1933, the BBB lost approximately $75 \%$ of its maximum vote share in 1928. From simple inspection of vote statistics, it is obvious that peasants exhibited no stable party attachments. ${ }^{10}$ The reason for this electoral volatility of especially small and midsize peasants is due to the evolving 
position-taking and policy-making of parties which were previously considered to represent the material interests of these segments (see Brustein 1996: $78 \mathrm{ff}$ ). Liberal parties (DVP and DDP) oscillated between free market positions and market interventions (agricultural tariffs). The party elites of the conservative party DNVP continuously revealed a clearer affinity to the large tenants in Eastern Germany. The Center Party was torn between its rural and urban voter constituencies. ${ }^{11}$ These discrepancies became evident in their enacted policies: "By late 1927 the government had begun preparing emergency assistance programs for the large estates in eastern Germany, but similar assistance for Germany's small and medium-sized farms were not given serious consideration until mid-1930" (Brustein 1996: 70). The Nazis realized these discrepancies and developed a highly effective campaign in the countryside. In order to appeal to peasant voters, Hitler modified the position of the NSDAP program by amending point 17 which promised the expropriation of land. He reframed it in such a way that it implied only illegitimately acquired land would be collectivized. In March 1930, the NSDAP proposed its first anti-crisis crash program for the whole of German agriculture. The agrarian program included policies relating to tax and interest reductions, reductions of food imports, and subsidies.

In summary, the interplay between an exogenous shock (the global agrarian crisis), longstanding structures of agriculture in Germany (rural stratification), and short-term decisions by the government led to a situation where the Nazi party was able to present itself as a credible party which represented the interests of small and mid- sized peasants. The NSDAP offered to overcome the particular numerous peasant parties which were too fragmented and powerless in the 1928 and 1930 elections. Thus, the disastrous failure of the system of German agricultural interest mediation (see Wehler 2008: 339, Jones 1986) was one major cause of the rise of the NSDAP. Small- and mid-sized farmers left their non-responsive parties and economically threatened farmers became susceptible to highly effective local and regional Nazi propaganda in the country-side. We will discuss the available empirical evidence for and against this argument below.

\section{Agricultural Structure and the Rise of the NSDAP: Main Quantitative Results}

There are surprisingly few quantitative analyses of the electoral success of the Nazi party which focus upon the influence of agrarian voters - as compared to the investigation of factors such as religious affiliation and unemployment. Originally, Falter considered the agricultural support of the Nazi movement as one of the most important open research questions (see Falter 1980: 187). One reason for this early focus was that studies at that time, such as Childers (1976), specifically investigated the urban origin of the Nazi voters. Second, the early studies by Heberle $(1934 / 1963,1946)$ and Loomis/Beegle (1946) were considered as too regionally focused and therefore not representative (see Falter 1980: 187). However, only one regional in-depth study of Franconia by Falter investigated the agricultural bases of the

11 Social Democratic Party as well Communist Party were, in any case, seen as the parties of expropriation and as backing the rural workers. 
NSDAP in a more detailed manner (Falter 1986). A summary of the national relationship between rural stratification and the Nazi vote is provided in Falter's book (1991: 256-266).

In the following, we briefly review the respective methodical approaches and the most important results of these studies. Heberle's study "Rural Population and National Socialism" was already completed in 1934. The sociological investigation of interest representation in Schleswig-Holstein (electoral district Nr. 14) from 1918 to 1932 is now a classic study in electoral research and in political geography. The starting point was the early and rapid breakthrough of the NSDAP in Schleswig-Holstein beginning with the election in 1930 . Before that election, Bavaria and especially Franconia (electoral district Nr. 26) exhibited the highest NSDAP shares. For the contemporary observer, it was obvious that the success in this region resulted from a radicalized peasantry. Inspired by the approach of electoral geography and using the method of an internal comparison across different agricultural regions in Schleswig-Holstein, Heberle attempts to identify the specific agro-economic incentives of the peasants. Specific soil conditions, modes of production and social stratification are considered to be crucial determinants of the radicalized voting behavior (see Heberle 1963: 41). Heberle proposes a series of highly-differentiated hypotheses, which are tested on the basis of 30 rural counties, and using rank correlation. The main result is that regions characterized by smalland medium-sized farms exhibited higher electoral shares for the NSDAP:

"More specifically, it may be said that the classes particularly susceptible for Nazism were neither the rural nobility and big farmers nor the rural proletariat, but rather the small farm proprietors, very much the rural equivalent of the lower middle class or petty bourgeoisie (Kleinbuergertum) which formed the backbone of the NSDAP in the cities." (Heberle 1945: 112)

And:

"It appears that the Nazis in 1932 had really succeeded the former liberal parties [...] as the preferred party among the small farmers (2-20 ha).” (ibd: 114)

Most importantly for our objective is the fact that Heberle already discusses in detail which farm sizes (Heberle 1963: 114) should be considered politically relevant with regard to the Nazi landslide. He proposes to treat the following combined original official categories of; "small and medium-sized" farms (2-20 ha), "large peasant farms" (20-100) ha, "large agricultural enterprises” with estates of more than 100 ha, as well as very small farms of 2 ha, the rural proletariat- as politically homogeneous strata. Note that these categories closely follow the predefined categories of the Official Statistics, which he considered a useful, sociologically based system of categorization. ${ }^{12}$

Loomis/Beegle (1946) extend their analyses to the regions of Hanover (electoral district Nr. 16) and Bavaria (electoral districts Nr. 24-26) in order to vary the confessional context. They came to the same conclusions as Heberle (1934/1963): "Elements of Nazism became entrenched among those rural middle-class controlled areas whose residents were suffering

12 See also the discussion of these categories by the sociologist Geiger (1932): 30-34. 
most acutely from economic insecurity and anxiety accompanying loss of social solidarity" (Loomis/Beegle 1946: 725). In his article "The rise of the NSDAP in Franconia in the elections 1924-1933”, Falter (1986) extensively investigates the relationship between agrarian structure and the Nazi vote in Franconia (electoral district Nr. 26) - a region with extremely high vote shares for the NSDAP in 1920s. Some authors considered Franconia a typical case study, whereas others have declared it to be atypical, therefore Falter aims to provide a systematic comparison of the explanatory power of the variables as applied to the Reich as a whole and to the Franconia, respectively. In Franconia, as for the Reich, Falter argues that the size of the agricultural sector is correlated with the share of Nazi votes ${ }^{13}$ in Protestant regions, beginning with the elections in 1932. This is contrary to the results of Heberle (and later Waldman), who state that the rural breakthrough had already occurred in 1930. Even more surprising is the fact that no relationship is demonstrated between mid-sized farms and the Nazi vote. This may be due to the author's method of operationalizing mid-sized farms. In contrast to Heberle, Loomis and Beegle, Falter regards the following farm sizes: 0-20 ha, 2050 ha, 50-100 ha as politically relevant. Relying on a 0-20 ha recombination of categories (see table 7 on p. 333), he detects rather small correlations in Franconia from 1924 to 1930 (0.39, $0.39,0.29,0.30$ ), shifting to negative correlations in 1932 and 1933. This runs counter to previous results and expectations. For the Reich, all respective correlations are below 0.20 in his article as well as later in the book (see 1991: 259). Partial correlation coefficients for the 0-20 ha category (controlling for shares of Protestants) become even highly negative for the 1932 and 1933 election in the article (1986: 333). Nevertheless, Falter concludes in the article that the hypothesis of the middle class character of the NSDAP in the countryside can be corroborated - at least from the election in July 1932 (Falter 1986: 335). This conclusion is mainly based on the use of the share of family workers as an indicator of family-based farms (see tables 7a and 7b, p. 333-334). Note, that in his book, Falter (1991) later revises his earlier conclusions of the 1986 article by demonstrating the weak correlation between family workers and NSDAP shares. ${ }^{14}$ Only in Protestant counties does the share of family workers appear to correlate with Nazi success (see Falter 1991: 261). In sum, Falter concludes here that there was no impact of farm sizes in the country-wide study (1991: 265). Note also that this far-reaching conclusion is now explicitly based on the variable of "average farm size" (1991: 265). Overall, the national testing of the different categories of farm sizes (0-20 ha, 20-50 ha 50-100 ha, and >100 ha) does not indicate substantial correlations. Remember, however, that Geiger (1932) as well as Heberle (1934, 1945, 1963) provide extensive discussions on why the political mentality of members of the category 0 -2ha - so-called parcel peasants - is completely different from the one of small and middle-sized holders:

"Farm sizes between 0.5 and 2 ha, are, at least on the country-side, held by day laborers and laborers for estates. Their income is mainly based on wages, whereas the usage of small pieces of land is part of this. Farms of this size occur mainly in districts with large estates.

13 Using Pearson correlation coefficients and shares of employed persons in the agricultural sector: for Franconia: all correlations are less than 0.2, for the Reich: correlations in 1932 are 0.21 and 0.22 respectively, and 0.43 in 1933.

14 See Falter (1991): 258, see also table 7.12 on p. 259 with correlations lower or equal 0.15. 
Thus, farm sizes of 0.5 to 2 ha and more than 100 ha are complementary.” (Heberle 1963: 115 , translation by the authors)

As a consequence, the relevance of the agrarian middle class for the success of the Nazis in the whole Reich is still an open question.

Political geographers (Flint 1998, 2001, O’Loughlin et al. 1994, 2002) have convincingly shown that the electoral performance of the NSDAP was highly variable locally and regionally. This spatial fragmentation is indicated by statistical dependencies which suggest an active construction of political spaces at that time. In line with the highly influential book by Cox (1997) 'Making Votes Count', we will argue that the 'electoral system', i.e. "the set of laws and party rules that regulate electoral competition between and within parties" (Cox 1997: 38) are the crucial mechanism of generating distinct political spaces. Electoral legal stipulations determine the specific method of translating votes into seats. They influence the interaction between partisan elites' local strategies and local cleavage structures. These rules determine the expectations of elites as well as of voters. A first crucial level of political coorientation have been the political territories (Lander and Prussian Provinces) of the Weimar Republic represented in the second federal chamber (Reichsrat, see Art. 60 of the constitution), They organized elections at the Lander level - and therefore constituted a natural relevant frame for the construction of political spaces. Second, according to the Law on the Electoral System (see especially Appendix of $\S 7$ (http://www.verfassungen.de/de/de19-33/reichswahl24-anlage.pdf)), the Weimar Republic consisted of $\mathrm{N}=35$ electoral districts (Wahlkreise) and of $\mathrm{N}=16$ so-called Associations of electoral districts (Wahlkreisverbände). Transferring votes into mandates required several steps where the aforementioned levels were crucial: electoral district lists received a mandate for 60000 votes (well-known). Although relatively unknown, the second step is highly important for strategic campaigning: the remaining votes in a electoral district ( $>60000)$ were added up within these Associations of electoral districts. This implies, that campaign strategies can be expected to be more homogenous within electoral districts and within such Assocations of electoral districts. Thus, geographic clustering should occur especially at the level of electoral districts and Associations of electoral districts. In terms of how political spaces are constructed, this means that rational parties and candidates take into account the rules of the electoral system when targeting tactically mobile voter segments.

\section{Hypotheses}

In line with the conclusions of Heberle (1934), Geiger (1932), Loomis/Beegle (1946) and Linz (1976), we expect that middle farmers (5-20 ha) were especially vulnerable to the rural campaigns of the NSDAP. Due to its specific structural economic position and confrontation with the structure of the party systems, this stratum was highly electorally unstable as it had no long-term loyalties towards mainstream parties in the established German cleavage structure (see Shively 1972, Linz 1976). As the Christian-national Peasant Party / German Peasants (Christlich-Nationale Bauern- und Landvolkpartei (CNBP ) / Deutsches Landvolk) were successful in 1928 and 1930 at organizing small- and middle farmers, we expect the major rural breakthrough of the Nazis to occur only in 1932. The political representation of 
the proprietors of farmer-capitalist agricultural enterprises was mainly organized by the Protestant Conservative Party (DNVP), and the Catholic Parties (Center Party, Bavarian People's Party, Bavarian Peasants' Alliance) until the agricultural crisis. We formulate the following hypotheses to be tested with our new data:

Hypothesis 1 (Heberle 1934/1963, 1946, Loomis/Beegle 1946, Linz 1976, Brustein 1996 etc.):

The higher the proportion of middle peasants (5-20 ha), the higher the vote shares of the NSDAP since July 1932.

Hypothesis 2 (Heberle 1934/1963, 1946, Loomis/Beegle 1946, Linz 1976, Brustein 1996 etc.):

The higher the proportion of proletarian parcel peasants (0-2 ha), the lower the vote shares of the NSDAP.

Hypothesis 3a (Falter 1986, 1991):

The relationship between the proportion of proletarian parcel peasants (0-2 ha), small-sized peasants (2-5 ha), and middle peasants (5-20 ha) respectively, and the vote shares of the NSDAP is identical.

Hypothesis 3b (Falter 1986, 1991):

There is no relation between the proportion of the composite stratum (0-20 ha) with the electoral results of the NSDAP.

Inspired by mass theories, Waldman (1973) argued that Protestant voters in general and Protestant peasants were socially disintegrated, and therefore concluded: “...that religion intervened between strain and the political reaction to it, that is that Protestants reacted differently to strain than did Catholics." (Waldman 1973: 94). As a consequence, he expects a "continuum of Nazi voters" (1973: 123), and specified this hypothesis as an additional interaction term between the proportion of Protestants and the proportion of workforce in the agricultural sector. Following Brustein (1996) and King et al (2008) which rather accentuate the geographic variation of material interests, we transfer this hypothesis to our incentivebased approach of peasant voting and reformulate the Waldman (1973) conjecture as follows:

Hypothesis 4 (Waldman 1973):

There is an interaction effect between the proportion of middle peasants (5-20 ha) and the proportion of Protestants: The positive association between the proportion of mid-sized peasants and the vote shares of the NSDAP increases with the proportion of Protestants. 
In accordance with political geography inspired contributions (Flint 1991, 2001, O'Loughlin et al. 1994, 2002), we expect regionally clustered voting behavior. On the basis of arguments which emphasize the importance of electoral systems in the strategic coordination between elites and voters (Cox 1997), we expect that these political spaces are co-constructed as a consequence of the duality between the local distribution of policy preferences and campaign activities of parties. Therefore the boundaries between these spaces, follows the delineation of political territories of the Federation represented in the second federal chamber (Reichsrat), and, therein, the electoral districts and so-called Association of electoral districts:

\section{Hypothesis 5:}

There are distinct regional electoral spaces which are expected to follow established political territories of the federation and, therein, electoral districts and Associations of electoral districts.

\section{Data and Operationalization}

In the following analysis, we use election data for seven elections (1924-1933) in the Weimar Republic as provided by Falter. ${ }^{15}$ This data set also includes extensive socio-demographic variables, mainly based on census data for the years 1925 and 1933. In addition to the already available number of employees in the agricultural sector in 1925 and 1933, we had to collect detailed information with regard to rural stratification. Using the 1925 census, ${ }^{16}$ we put together data for the respective workforce of different farm sizes. We maintained the original categories of parcel farmers (0-2 ha), small farmers (2-5 ha), middle farmers (5-20 ha), large farmers (20- $100 \mathrm{ha}$ ), and large estate farmers with more than 100 ha. We also control for shares of Protestants, the degree of urbanization and the share of unemployed. With regard to socio-demographic data, we rely mainly on the 1925 census. For the unemployment rate, we use the 1933 census for the last three elections (1932-1933). In order to account for existing spatial effects (see Flint 1998, 2001, O’Loughlin et al. 1994, O’Loughlin 2002), regional indicator variables will be used. These regional indicator variables are designed to capture important electoral processes. They divide the Weimar Republic into 23 political regions based on preexisting administrative entities which approximate the electoral districts. ${ }^{17} \mathrm{~A}$ detailed list of the variables and regions is provided in the appendix. We expect the electoral districts to demonstrate similar campaign strategies internally and, therefore, to mirror correlated spatial processes.

5 Source Gesis, ZA8013.

16 Statistik des Deutschen Reichs (1929).

17 First we started with the 18-24 Laender of the Weimar Republic. However, Prussia, accounting itself for 3/5 of the territory, was extremely heterogeneous composed. This is the reason why Falter et al (1986:86) proposed to consider in this case additionally the Prussian provinces and their specific elections. We follow this suggestion. The Laender and the provinces also correspond quite closely to the electoral districts $(\mathrm{N}=$ 35). In a second step we combine several Laender / provinces. Our final regions, see Table 6 in the Appendix, are a mixture between Association of electoral districts and electoral districts while conserving the political territories of the Weimar Republic. 
Like Falter (1991), we apply all models at the county level (Kreise). Changes of the boundaries of counties over time, i.e. the complete or partial fusion of two counties, necessitated the merging of some of the counties. For the analysis, information for 849 counties will be available.

The share of the NSDAP vote is our dependent variable. Percentages are based on the number of those being entitled to vote. In order to visualize the electoral geography of the Nazis and the spatial distribution of our key variable - the spread of mid-sized farms - we created a digital map of the Weimar Republic including all counties. ${ }^{18}$ We fitted models for every individual election in the period 1924 to 1933.

\section{Statistical Model}

Contrary to contributions aiming to make inferences from the aggregate data level to individual behavior, ${ }^{19}$ we are striving for the following methodical objectives:

1. We will provide the first critical test of whether counties characterized by mid-sized farms (5-20 ha) were susceptible to Nazi propaganda to a higher degree than counties characterized by other farm sizes. As the only country-wide test by Falter $(1986,1991)$ used a "composite" variable (0-20 ha), we are the first to separate the impact of different rural strata on the Nazi vote.

2. We will for the first time account for political spaces by including indicators for electoral districts, which is expected to capture spatial autocorrelation.

3. We will apply for the first time advanced generalized additive models (GAM) to the ecological analysis of the Nazi vote.

Thus, we do not intend to draw direct conclusions from the aggregate level to the individual level. Our estimated effects will only indicate whether and how the proportion of mid-sized peasants in the counties covary with the electoral outcome of the NSDAP.

To our knowledge, we are the first to apply a generalized additive model (GAM) for this objective. $^{20}$ This statistical approach has the advantage that no restrictive prior assumptions with regard to the relationship between the covariables and the response have to be made. The relationship is calculated as a smooth function with the exact form defined by the data. For the estimation we are using penalized splines. ${ }^{21}$ Due to the large number of covariables, a restrictive number of knots has been chosen. ${ }^{22}$ Models were fitted by applying the empirical

18 Based on a map in Statistik des Deutschen Reichs (1929).

19 See e.g. King et al. (2008).

20 GAMs were originally proposed by Hastie and Tibshrani (1986). See also Beck and Jackman 1998. A useful recent overview is provided by Keele (2008).

21 For detailed explanations, see Eilers and Marx (1996) and Ruppert, Wand and Carroll (2003).

22 Five knots were chosen. Thus, an acceptable data-to-degree-of-freedom ratio higher than 1 to 10 can be preserved. 
Bayesian approach implemented in BayesX. ${ }^{23}$ From this family of models, we implemented the general additive logistic regression model adjusted for overdispersion. For the comparison of models we are relying on the generalized cross validation score (GCV). ${ }^{24}$ Each election was considered independently. The models are of the following form:

$$
\begin{aligned}
\log \left(\frac{\pi_{i}}{1-\pi_{i}}\right) & =\beta_{o}+\beta_{r, i} \\
& +s_{B 0-2 \mathrm{ha}}\left(x_{B 0-2 \mathrm{ha}_{i} i}\right)+\ldots+s_{\text {urb }}\left(x_{\text {urb. }, i}\right)+\left[s_{\text {umempl }}\left(x_{\text {unempl }, i}\right)\right] \\
& +f_{B 5-20 \mathrm{ha}}\left(x_{B 5-20 \mathrm{ha}, i}\right)
\end{aligned}
$$

$\pi_{i}$ is the proportion of NSDAP voters in county $i . \beta_{0}$ is the global intercept. The spatial part consisting of the regional indicator variables is represented by $\beta_{r, i}$. Smooth functions are estimated for all metric control variables. Terms in squared brackets are not included in all models. The main model consists of the percentage of Protestants, the share of parcel peasants (0-2 ha), the share of small peasants (2-5 ha), the share of middle peasants (5-20 ha) and the share of large farmers (20-100 ha), percentages of workers, workers in industry and handcraft, and the urbanization level. The 1933 unemployment rate is exclusively considered in the models for the three elections 1932-1933.

As the relationship $\left(s_{B 5-20 h a}\left(x_{B 5-20 h a}\right)\right.$ (1a) proved to be almost linear, additional models with linear middle farmer components $\left(\beta_{B 5-20 h a}\right)(1 \mathrm{~b})$ for the elections $1930-1933$ are also provided. The test of hypothesis 4 requires a different approach: To estimate the possible changing effect of the middle farmer percentage depending on the percentage of Protestants, a varying coefficients $\left(\beta_{B 5-20 h a}\left(x_{\text {Prot }}\right)\right)(2)$ approach (Hastie/Tibshirani 1993) is chosen. Again, a smooth functional relationship between the $\beta_{B 5-20 h a}$ and the percentage of Protestants is specified, and given the estimated function for each $x_{P r o t}$, a separate $\beta_{B 5-20 h a}$ can be extracted from the model.

To identify spatial autocorrelation between the covariates and the residuals we are using Moran's $\mathrm{I}^{25}$. Note also, that the model specification of GAM automatically implies a weighting of the number of eligible voters in a county by using the binomial distribution.

\section{Descriptive Analysis}

A brief description of the relationship between our main variables, i.e. between the share of farmers with mid-sized farms (5-20 ha), and the proportion of the NSDAP in the respective elections, is depicted by the respective scatterplots in Figure 1. There is no detectable pattern in the period from 1924 to 1930 . In the 1924 and 1928 election, it can be seen, that the NSDAP receives higher vote shares in districts with low percentages of mid-sized farms.

23 Belitz et al.(2009), Fahrmeir, Kneib and Lang (2004).

24 Craven and Wahba (1979).

25 Using a binary neighborhood structure (shared border) and row standardized weights. 


\section{Election May 24}

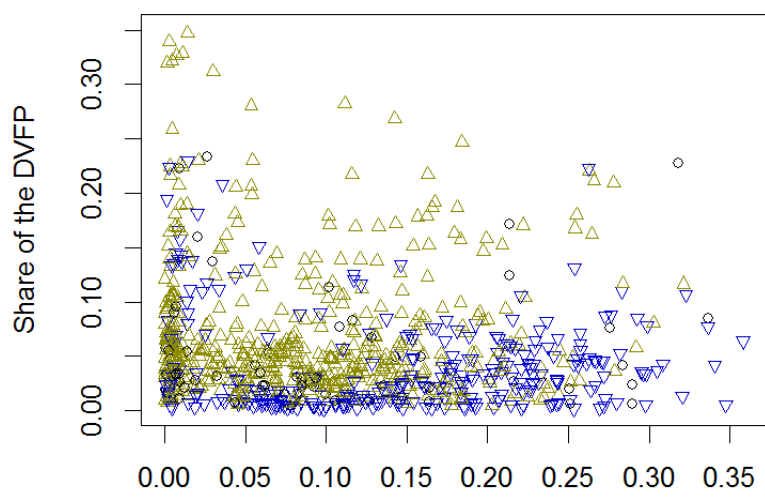

Election Sept 30

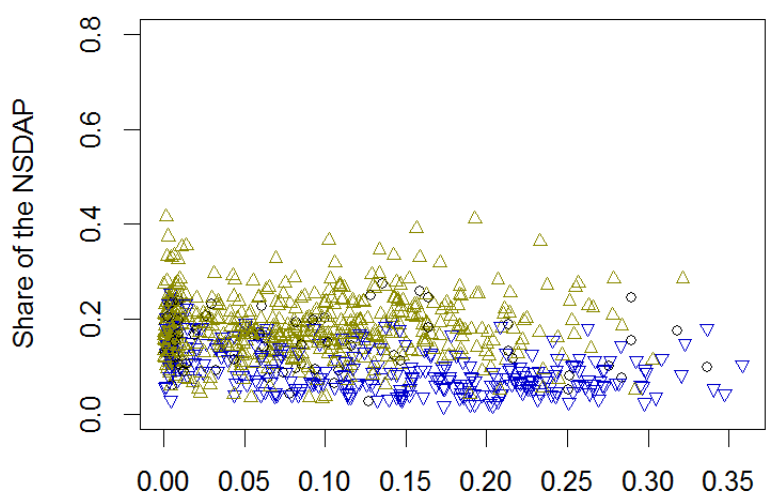

Election Nov 32

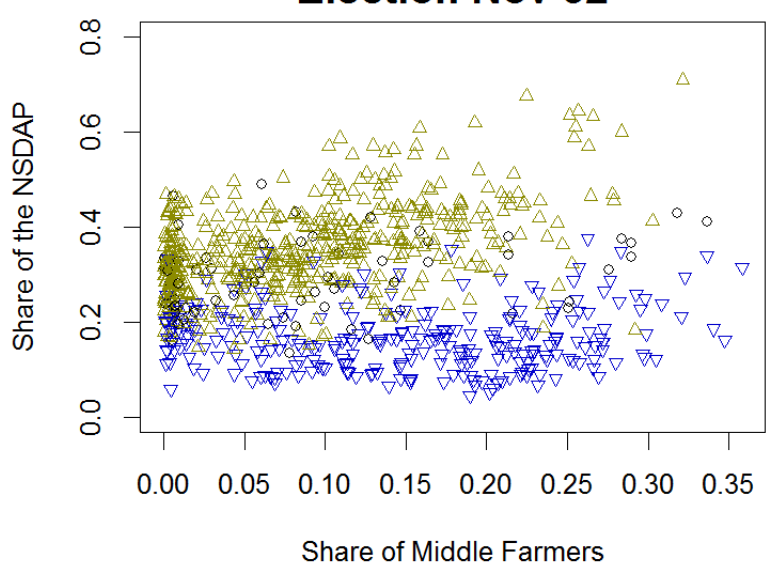

Election May 28

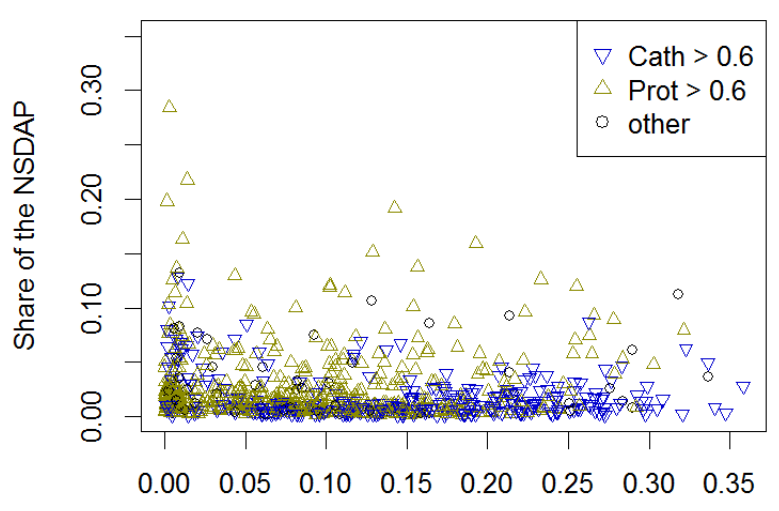

Election Jul 32

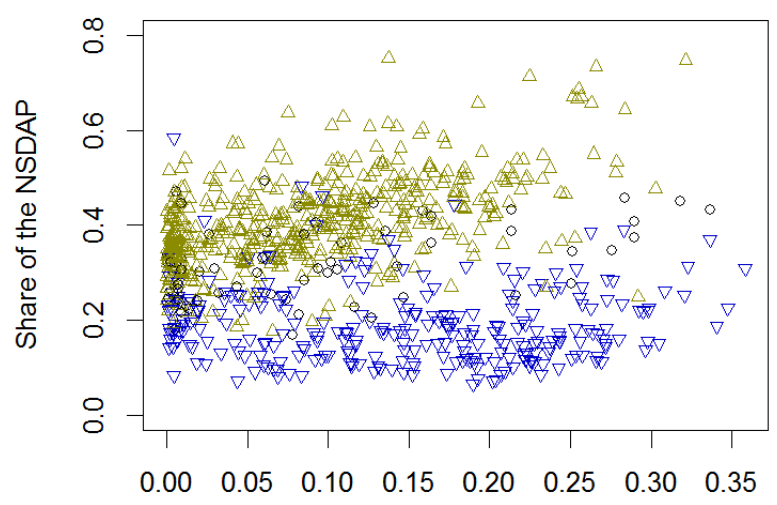

Election Mar 33

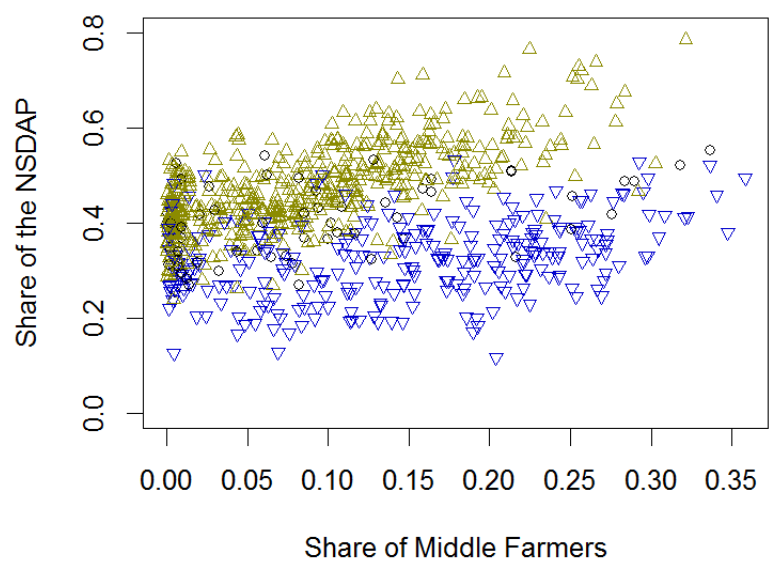

Figure 1: Share of Middle Farmers (5-20 ha) and Election Results of the NSDAP

This is the period when the Nazis had their strongholds in the cities instead. In the September 1930 election, this pattern becomes a clear non-relation, indicating that the urban-to-rural realignment (Waldman 1973) is clearly under way, but in no way yet complete. Note the different scaling of the $y$-axis, which is due to the enormous growth of this party already in this election. 
The expected relationship becomes visible for the first time in the July 1932 elections. In order to explore visually whether there is indeed an interaction effect between high shares Protestants and (these) rural segments (Waldman 1973), we colored cases according to their dominant confessional affiliation.

In our analysis it became clear that the two groups had already started to separate in the 1930 election. This tendency steadily sharpens until the final 1933 election. A nearly monotonically increasing functional form of the Catholic data cloud, however, becomes obvious only in this last election.

Comparing these figures with the ones where the $\mathrm{x}$-axis is represented by the share of small farmers (2-5 ha) (see appendix: Figure 9), a very similar tendency appears. In contrast, a comparison with proletarian parcel farmers of 0-2 ha (see appendix: Figure 8) demonstrates a completely different development. This may be a first indication that a combination of farms of 0-20 ha is not appropriate due to behaviorally different populations.

Table 2: Correlation Between Percentages of Workforce in Different Categories

\begin{tabular}{|c|c|c|c|c|c|}
\hline & $0-2$ ha & $2-5$ ha & 5-20 ha & 20-100 ha & $100+$ ha \\
\hline $0-2$ ha & 1.000 & 0.479 & 0.073 & 0.021 & 0.166 \\
\hline $2-5$ ha & & 1.000 & 0.610 & -0.003 & -0.199 \\
\hline 5-20 ha & & & 1.000 & 0.450 & 0.015 \\
\hline 20-100 ha & & & & 1.000 & 0.380 \\
\hline $100+$ ha & & & & & 1.000 \\
\hline
\end{tabular}

Table 2 presents the correlation matrix for shares of the different farm sizes. Commonly, a moderate correlation exists between the agriculture variables for neighbor groups, whereas the correlation between the non-neighbor groups is generally low. The largest correlation can be observed between the occurrence of small and mid-sized farms (0.61). Note that the correlation between the occurrence of parcel peasants (0-2 ha) and mid-sized (5-20 ha) peasants is extremely low: 0.073. We interpret this as a second indication that these two categories should not be combined. There is a slightly larger correlation between proletarian parcelists and the large estates - just as Heberle (1963) observed and Linz (1976) expected.

Figure 2 presents the electoral geography of the NSDAP for the November 1932 election when the urban-to-rural shift was under way. We use a smooth color gradient ranging from full white to full gray. Some regions, especially parts of East-Prussia, Silesia and Bavaria exhibit comparatively lower results for the NSDAP. 
Commonly, this structure mirrors the confessional structure of the counties. In counties that were predominantly Catholic, the NSDAP had lower results in this election, whilst in counties that were predominantly Protestant, the NSDAP achieved higher results. Therefore, most studies analyzing these elections so far concluded that the religious affiliation is the main determinant explaining the success of the NSDAP.

However, the geographic spread of the rural structure may have a distinct and separate impact on the Nazi vote. Therefore, Figure 3 shows the corresponding percentages of the workforce in mid-sized farms (5-20 ha). The Southern part of the Reich is characterized by high percentages of middle peasants, but this is also seen in northern areas, such as Hanover. Visual inspection also shows that the agricultural structure varies to a higher degree within electoral districts as compared to shares of the NSDAP.

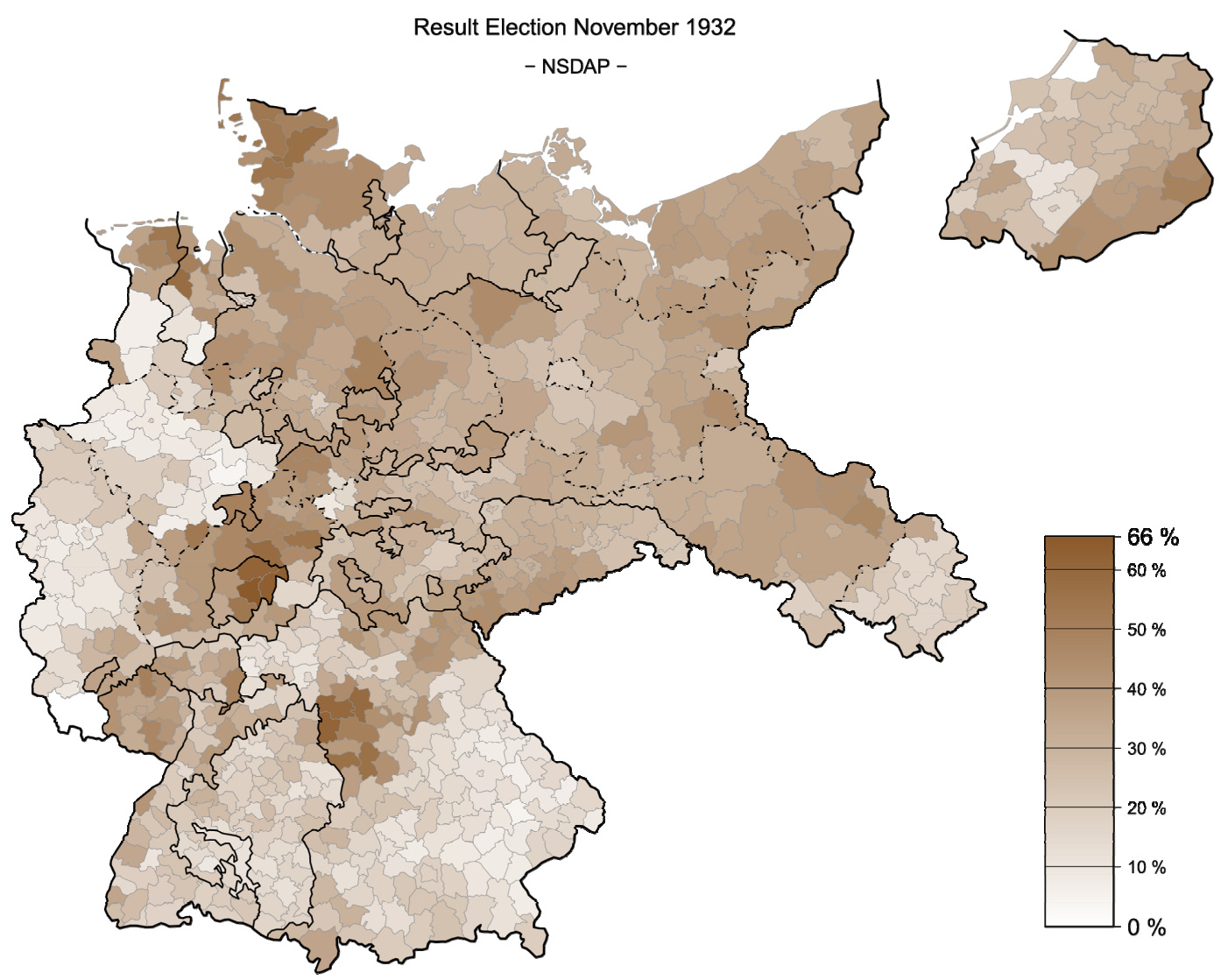

Figure 2: Elections Results NSDAP, November 1932, Sources: Statistik des Deutschen Reichs (1929) and Gesis ZA8013 


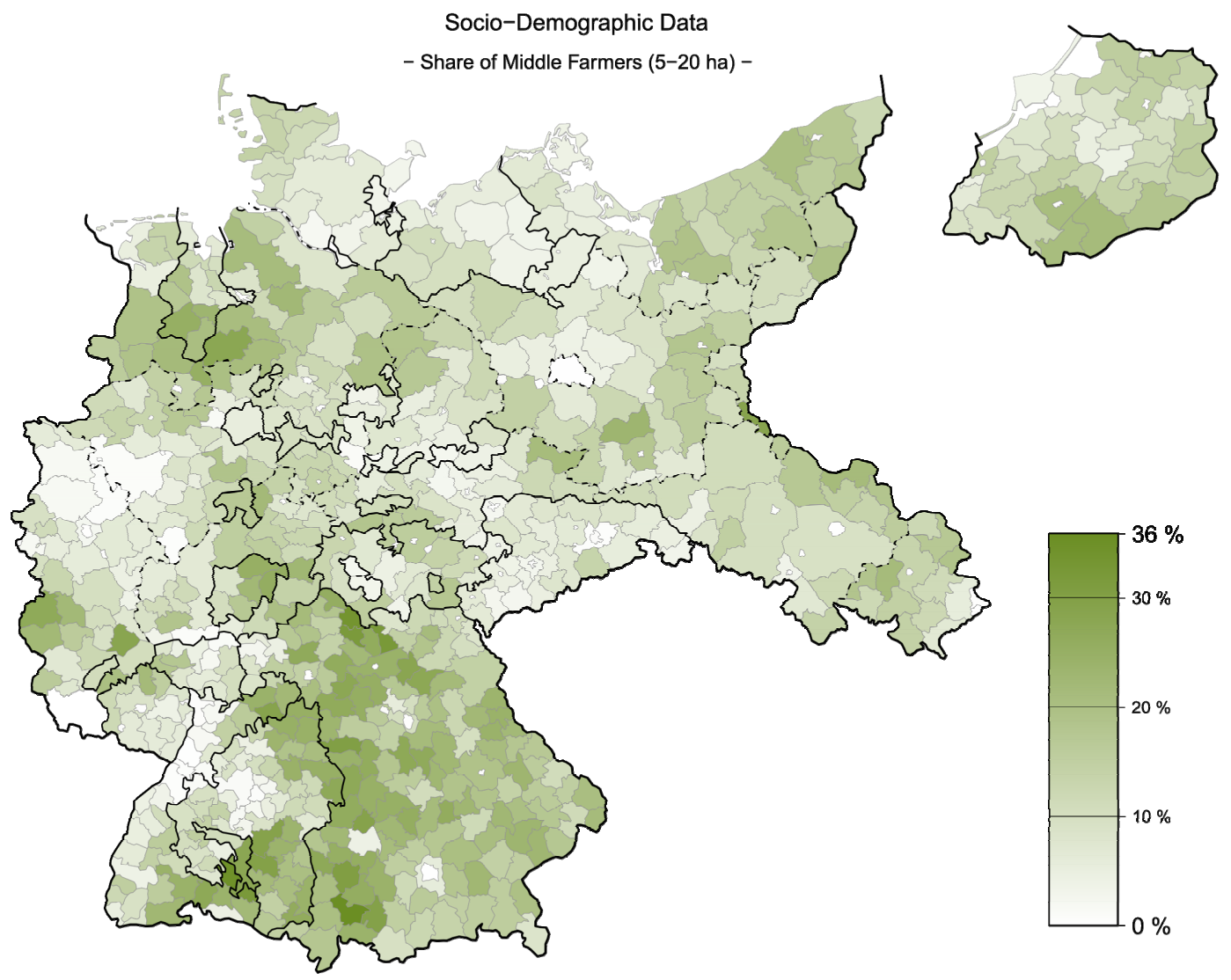

Figure 3: Workforce in Middle Farms (5-20 ha), Sources: Statistik des Deutschen Reichs (1929) and Census 1925

Therefore, the construction of political spaces seems not to be fully determined by the agricultural structure. Next we proceed to a multivariate test of our hypotheses.

\section{Model Results}

The following figures present the key results of the models (1a). We only present the effects for four elections: May 1928, September 1930, July 1932 and March $1933{ }^{26}$ In order to compare the impact magnitude of middle farmer percentages (Figure 5) with the wellestablished influence of confessional affiliation patterns, we first present the estimated smooth functions for the percentage of Protestants (Figure 4). We display identical y-scales.

The relationship between the proportion of Protestants and the NSDAP is clearly strong, and exhibits a time-stable similar-shaped non-linear function. This association is only slightly weakened over time. The general shape of the relationship is very similar for all elections.

The picture is clearly different for the middle farmers (5-20 ha). The estimated effect is evidently not identical over time. In the election 1928, a negative association between the

\footnotetext{
${ }^{26}$ Due to space limits, results for all other variables and elections are presented in the appendix.
} 

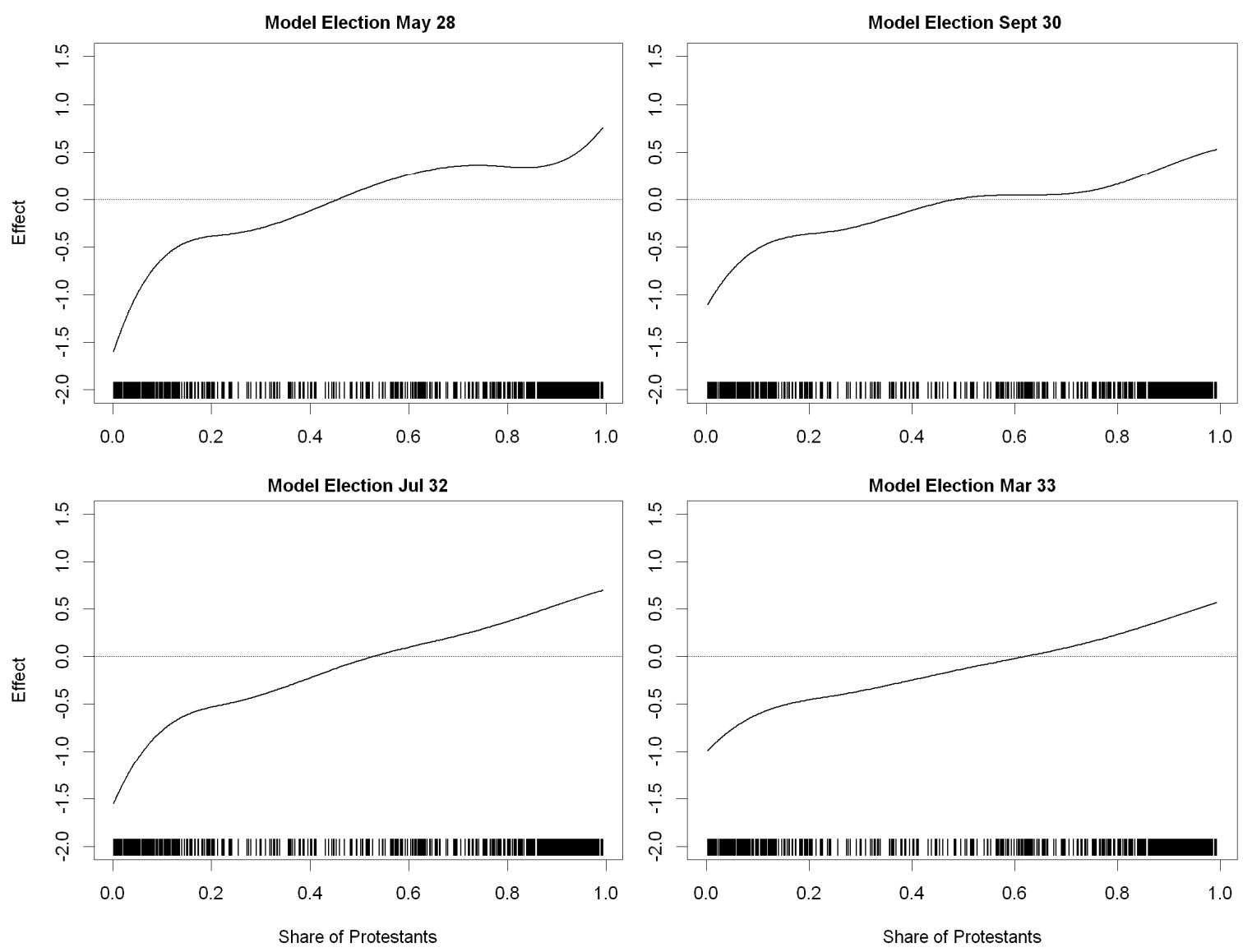

Figure 4: Estimated Smooth Effect of the Share of Protestants on the Share of the NSDAP

shares of middle farmers and NSDAP voting can be seen. The success of the NSDAP is higher in counties with a small share of middle farmers. In the 1930 election, there is almost no association between the share of the middle farmers and proportion of NSDAP. However, for the elections in July 1932 and March 1933, a clear positive, almost linear association becomes obvious: The success of the NSDAP is increasing with the share of the middle farmers.

Therefore, we conclude, that hypothesis 1 is corroborated by this data. As the functions for the last four elections resemble a linear relationship, we additionally estimated separate models (1b) with a parametric linear middle peasant component for this elections (see Table 3).

This estimation provides an unambigous positive coefficient, where the size changes from September 1930 to July 1932 by a factor of approximately 6 ! If we consider two fictional counties, which only differ in their middle farmer share, we can elucidate the estimated effect. If we assume that county 1 has $0 \%$ and the county 2 has 30\% middle farmers then using the coefficient of July 1932, i.e. the value of 1.544, the odds for the NSDAP shares are 1.59 times higher for county 2 . If county 1 would have a NSDAP share of $20 \%$, we can expect a share of $28 \%$ in county 2 . In sum, we conclude that hypothesis 1 is corroborated - non-parametrically as well as parametrically. 

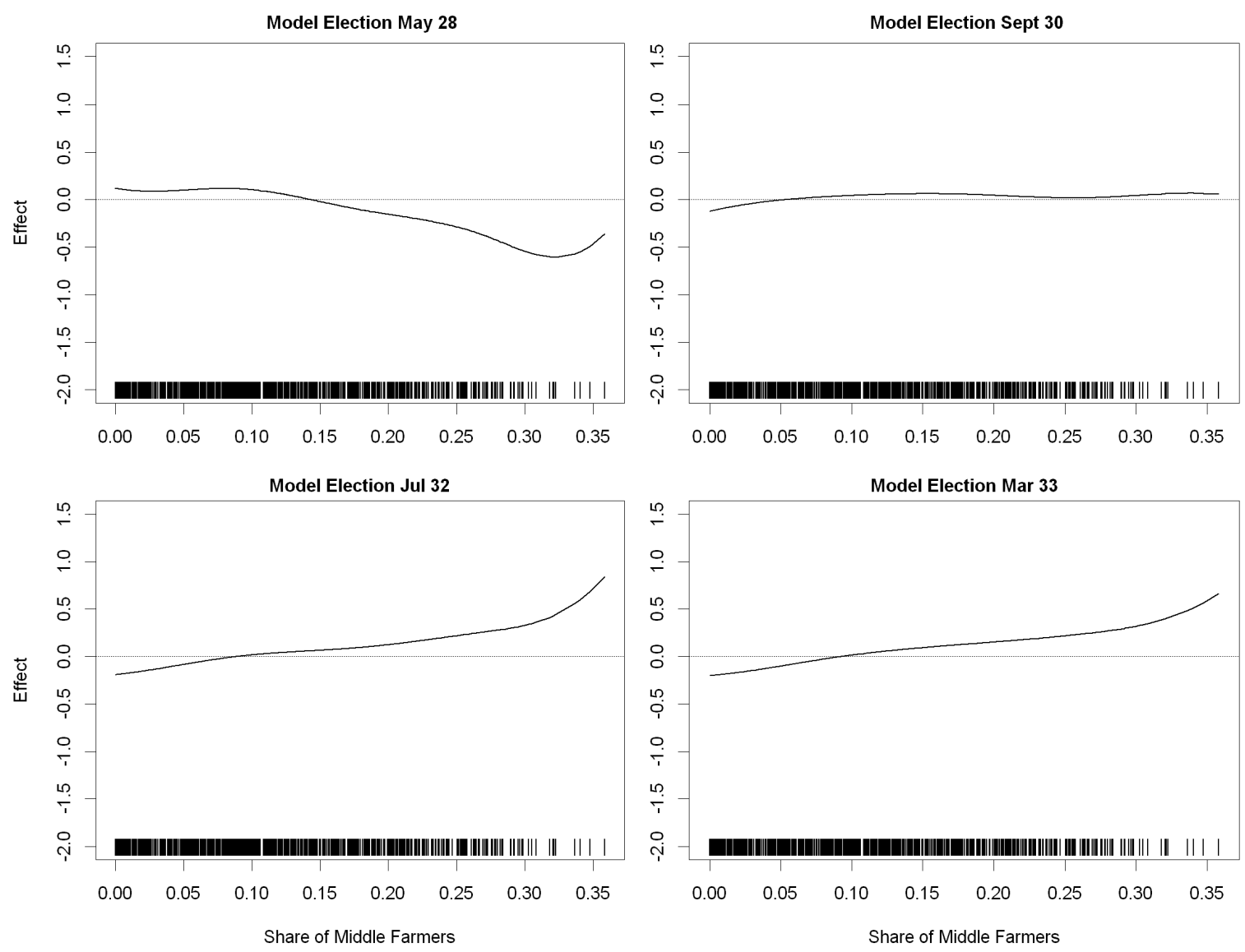

Figure 5: Estimated Smooth Effect for the Share of Middle Farmers (5-20 ha) on the Share of the NSDAP

According to our estimation results (see appendix: Figure 23), neither small farmers (2-5 ha) nor proletarian parcel peasants ( $0-2 \mathrm{ha}$ ) exhibit the same positive relationship as the middle farmers in the three elections 1932-33. Whereas for the small farmers a similar negative relationship can be identified for the 1924 and 1928 elections, no relationship can be detected for the elections 1930 and 1932-1933. Contrary, the estimated function for the parcel farmers even reveals a small positive relationship for the elections until 1930. However, there is no effect for the elections 1932-1933. Therefore, we conclude, that hypotheses 2 and 3a have to be refuted.

Table 3: Estimated Parameters for Middle Peasant Shares (Excerpt of the Full Model)

\begin{tabular}{|l|l|c|c|}
\hline Election & Point estimate & \multicolumn{2}{|c|}{$95 \%$ - Confidence Interval } \\
\hline Sept 1930 & 0.258 & -0.747 & 1.264 \\
\hline July 1932 & 1.544 & 0.819 & 2.268 \\
\hline Nov 1932 & 1.817 & 1.015 & 2.620 \\
\hline Mar 1933 & 1.696 & 1.024 & 2.369 \\
\hline
\end{tabular}




\section{The Experimentum Crucis: Is Combining Farm Sizes 0-20 ha Appropriate?}

In the so far sole country-wide study which investigates the hypothesis of a middle peasant impact, Falter $(1986,1991)$ combined the categories of the Official Statistics of the German Reich for proletarian parcel peasants (0-2 ha), small peasants (2-5 ha) and middle peasants (5-20 ha). We already presented several findings that indirectly contradicted this research strategy and, thus, question the far-reaching conclusion according to which there was no middle-stratum-related voting behavior on the countryside.

This conclusion actually constituted a revision of the important results of Heberle (1934/1963, 1946), Loomis/Beegle (1946) and many other scientists. In order to show that the combination of these categories is inappropriate, we specify exactly this composite variable (0-20 ha) with the same model as before, just replacing the separate variables (see Figure 6). For the 1928 election, we see a weak negative relationship, with a local maximum at 12-14 percent. For the 1930 election, the estimated function is a rather horizontal line. Most importantly, for the elections July 1932 and March 1933, only a minor positive effect is visible, mainly for percentages of the composite variable mid-sized farmers higher than 50 percent. A comparison of the strength of the estimated effect shows that the combined consideration
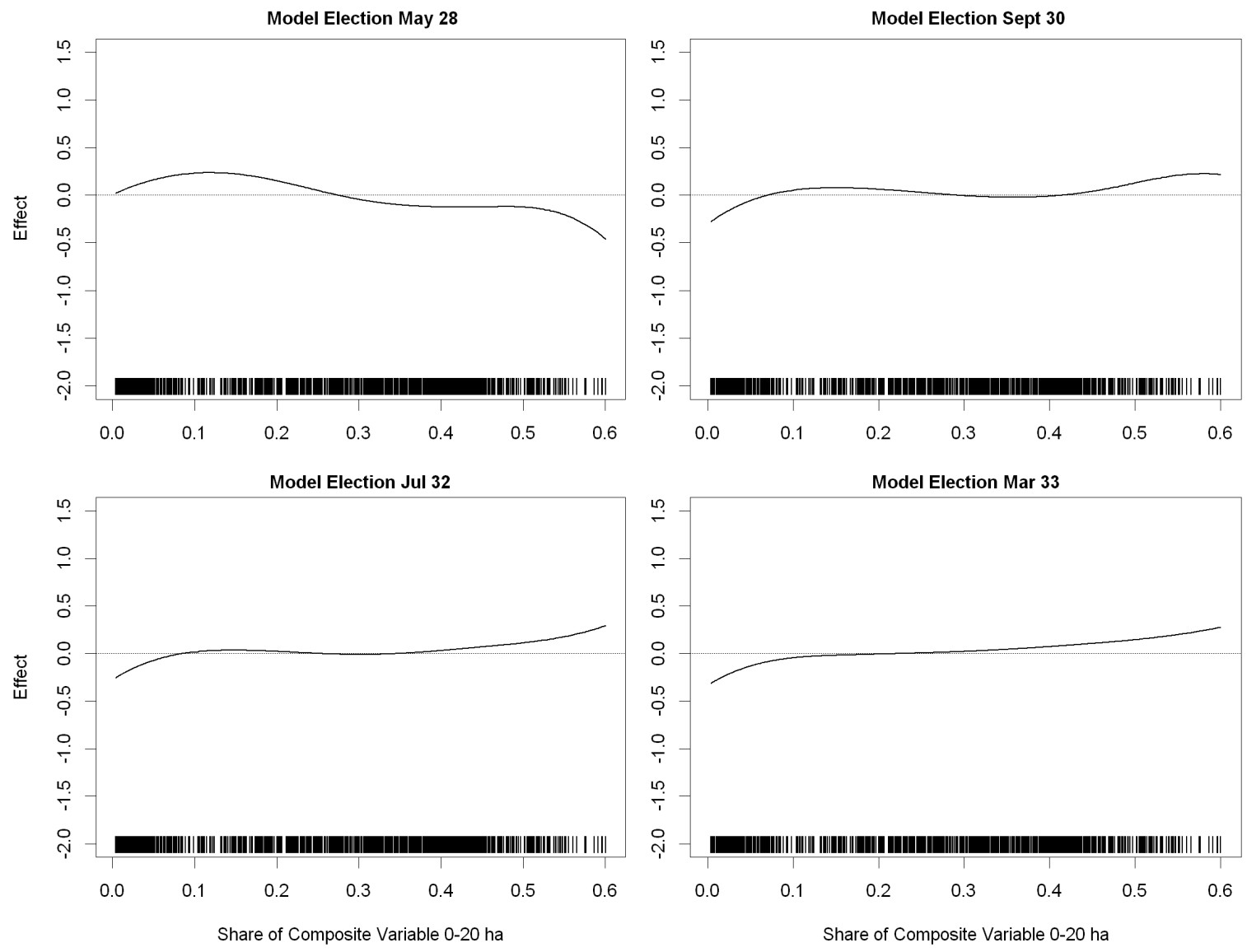

Figure 6: Estimated Smooth Effect for the Composite Variable (0-20 ha) on the Share of the NSDAP 
reduces a clear positive effect to a non-effect. We conclude, therefore, that hypothesis $3 \mathrm{~b}$ cannot be refuted. In conjunction with our results for hypotheses 1, 2 and 3a, we deduce that the measurement of middle peasants via a composite variable (0-20 ha) is inappropriate.

In order to allow a direct comparison with the linear coefficients fitted for the middle farmers (5-20 ha) for the elections 1930-1933, linear models were also fitted for the composite variable (0-20 ha):

Table 4: Estimated Parameters for the Composite Variable (Excerpt of the Full Models)

\begin{tabular}{|l|l|c|c|}
\hline Election & Point estimate & \multicolumn{2}{|c|}{$95 \%$ - Confidence Interval } \\
\hline Sept 1930 & 0.086 & -0.361 & 0.533 \\
\hline July 1932 & 0.260 & -0.067 & 0.588 \\
\hline Nov 1932 & 0.420 & 0.056 & 0.784 \\
\hline Mar 1933 & 0.543 & 0.239 & 0.847 \\
\hline
\end{tabular}

By comparing these results with the estimates in Table 3, it is possible to identify striking differences. The estimated coefficients are obviously much smaller for the composite variable. Additionally, there is no overlap between the estimated confidence intervals for the last three elections as compared to Table 3. This indicates that there is a significant difference between the estimated effects, and the combined consideration of the different farm sizes is not justified.

Comparing the generalized cross validation scores (GCV) of the seven smooth models for the separate middle farmer category (5-20 ha) and the composite variable (0-20 ha), almost identical value can be found in the December 1924 and September 1930 election models. For all other elections, the GCVs for the models with separate middle farmer category are lower, with the largest numeric difference occurring between the models for the two elections in 1932.

In addition to the model with a separate specification of middle peasants (5-20 ha), we also examined whether the combination of small and middle farmers into one group (2-20 ha) changes the result. Note, that this resembles the strategy of Heberle $(1934 / 1963,1946)$ and Loomis/Beegle (1946) for their regional studies. We found only minor differences as compared to the exclusive specification of the middle peasants (5-20). Based on the separate estimated results for the small farmers (2-5 ha) which showed almost no effect for the elections 1930-1933, we conclude that a separate specification of middle peasants (5-20) is most appropriate.

\section{Testing Waldman's Continuum Conjecture for the Case of Middle Peasants}

Is there an interaction effect between the share of Protestants and the share of the agricultural sector? Based on bivariate correlations and tree analyses, Falter concludes that Waldman was correct in expecting that "the NSDAP shares increase more or less steadily/monotonically from the rural Catholic precincts to the rural Protestant districts, with the urban precincts in- 

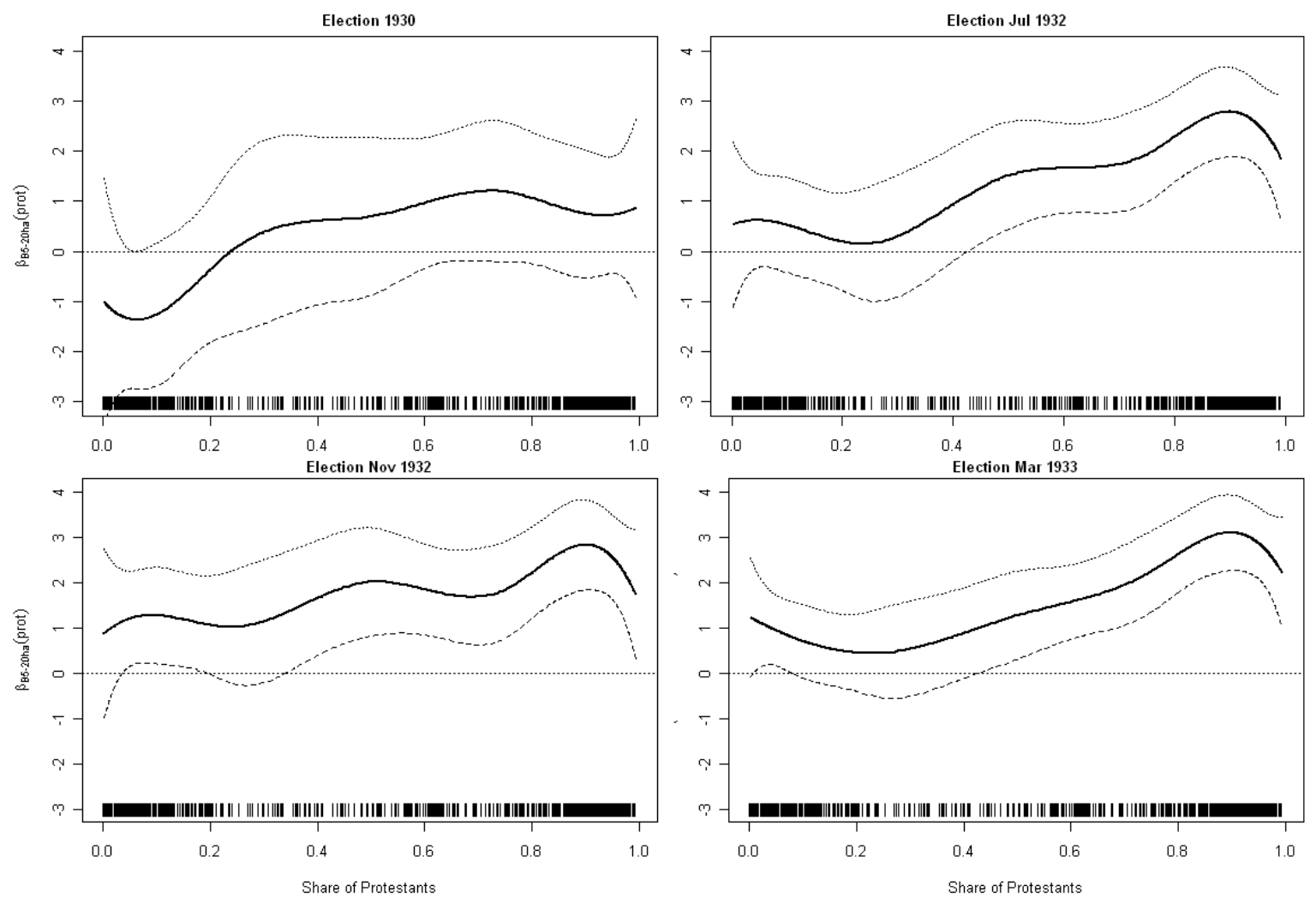

Figure 7: Estimated Smooth Linear Coefficients Function for the Share of Middle Farmers Depending on the Percentage of Protestants with 95\% - Confidence Interval

between on this continuum” (Falter 1986: 327). We test the Waldman hypothesis, for the first time using the share of middle peasants (Hypothesis 4).

Applying the GAM approach, we specify a model (2) with varying coefficients (Hastie/Tibshirani 1993) for the last four elections separately in order to test whether the share of Protestants was an "effect modifier". For each percentage point of Protestants, the linear coefficient for the middle farmers is now presented.

All four functions display a positive relationship between the middle peasant coefficient and the percentage of Protestants. For the 1930 election model, no effect can be detected, as the whole $\mathrm{x}$-axis is in the confidence interval. The functions for the last three elections indicate that the positive association, i.e. the coefficient of the share of the middle peasants increases when the share of Protestants is higher. This effect is most pronounced in the election in 1933. Only in almost completely homogenous Protestant districts, does this relationship weaken. In conclusion however, these results clearly corroborate Waldman's expectations for the 1932-1993 elections.

\section{Regional Electoral Spaces}

Finally, we assess the potential of our hypothesis according to which electoral districts and the stipulation for Associations of electoral districts allow us to distinguish spatially distinct 
political spaces - and to absorb thereby effectively spatial heterogeneity as well as spatial autocorrelation.

The results of the estimation are presented in Figures 16 - 22 and Table 7 in the appendix. We display point estimators of the logistic regression model. For the visualization, the estimated effects are centered in order to avoid interpretation with regard to a reference category, and to ease comparison between the elections. Since the coefficients for the elections in 1924 and 1928 have relatively high values as compared to the following elections, different scales are used for these three elections. Positive coefficients (colour blue) relate to higher shares of the NSDAP in the respective region. More specifically, a coefficient of 0.5 means that the odds of voting for the NSDAP are increased by the factor $\exp (0.5)=1.65$ as compared to a region with coefficient 0 after adjustment for all variables in the model

Both elections in 1924 had a similar the pattern. Some regions, especially Bavaria, province Posen and Mecklenburg-Schwerin / Mecklenburg-Strelitz exhibit strong positive effects, while most regions have small or strong negative effects. The general picture changed in the 1928 elections. While the strongest effects can still be found in Bavaria, further positive coefficients are now primarily in the western part of the Weimar Republic. Another region with a strong positive effect is the state Oldenburg. A strong contrast between the regions continues to be visible.

The estimated regional effects for the 1930 election are much lower than for the elections 1924 - 1928. While the general landscape remains similar, the contrast between the regions is now lower. A notable change is that in the eastern part of the Weimar Republic, the province lower Silesia exhibits a positive effect. Bavaria manifests the highest positive deviations, while the neighbouring Württemberg offers the strongest negative effect. Notable differences can be identified in the July 1932 election. While still demonstrating positive affinities to the NSDAP, Bavaria no longer shows the highest deviation. Regions in the eastern part of the Weimar Republic have positive coefficients. The general shape of the estimated electoral is similar for the election in November 1932. However, our analyses of the election in March 1933 indicate remarkable differences. Disparities between the regions become even lower.

Overall, Bavaria manifests positive differences in all seven elections. The estimated effects are the strongest in the first elections and converge to the average in the later elections. The estimated effects for the southern part are always higher than the effects for the northern part. Another constant are the negative effects for the state Württemberg. In other regions, the size and also the sign of the effects change. For example, some of the regions, which can be considered as strongholds in the first elections, have negative coefficients in the last elections. In sum, our approach, using the Associations of electoral districts while still conserving the political territories as closes as possible proved to be highly appropriate for the description of the electoral space. There are highly distinct regions in the early years. However, the amount of differences decreases over the years thus indicating an assimilation of political spaces.

The theoretically justified choice of our regional indicator variables absorbs spatial autocorrelation quite well. As a consequence, the residuals exhibit only small correlations. We present the maps of the residuals for the models (1a) for the last four elections in the appendix 
(see Figures 26 - 29). Moran's I values for this models are 0.24 (Sept 1930), 0.29 (July 1932), 0.28 (Dec 1932), 0.25 (Mar 1933) indicating some minor remaining additional spatial structure. $^{27}$ As spatial effects do not run counter to our main hypothesis, and the share of middle farmers which is our main variable of interest, also has a spatial structure with a Moran's I value of 0.40 , we decided to follow the argumentation of Wakefield and included no further spatial effects. ${ }^{28}$

\section{Discussion and Conclusion}

The higher the share of middle peasants (5-20 ha), the higher the success of the Nazi party since the July 1932 election. With this new finding, we contribute one very important facet to the understanding of the electoral success of the NSDAP: The swing towards the NSDAP in the 1930s had also a rural basis, and this was more pronounced in counties with higher proportions of agrarian middle classes. Therefore, the rural voter transitions had a clearly asymmetric structure. As a result, these results crucially improve our understanding of the socio-economic and geo-structural bases of the failure of the Weimar democracy. Surprisingly, this is the first statistical analysis ever to test this specific relationship for the whole country based on low-level county (Kreise) data. We have argued and empirically substantiated this hypothesis with new and original data, which indicate that previous (non-)results of Falter (1986, 1991) are inconclusive - due to a non-justified recombination (0-20 ha) of the original categories of the official statistics. Our results are in line with other previous results for selected regions, e.g. by Heberle (1946, 1963) and Loomis/Beegle (1946). The rural Nazi vote since at least 1932 has been higher in counties characterized by farm sizes of 5-20 ha. This is due to the high congruence between the programmatic offers of the Nazi Party and the politico-economic interests of this segment. However this occured only after previous natural supply parties like the liberal parties DDP, DVP, the Conservative Party DNVP and, to a lesser degree, the Center Party were considered incredible during the course of the agrarian crisis by middle peasants. Obviously, proletarian parcel farms as well as small farmers had distinct politico-economic incentives as compared to middle farmers. ${ }^{29}$ The failure of the political supply side during the agrarian crisis made this latter segment especially vulnerable to the aggressive campaign of the Nazis at the countryside. Naturally, this campaign proved to be effective to varying degrees as we can see from our new indicators capturing relevant political spaces, i.e. electoral districts.

From a macro-sociological perspective, these new insights are highly important. Here, the peasantry is attributed a crucial role in the process of modernization, of democratization, of political crises, and of revolutions (see Moore 1966, Huntington 1968, Taylor 1988, Skocpol 1979). According to Wolf (1969), it's the "middle peasantry" which is the "tactically mobile peasantry.” The author explains this fact by the discrepancy between a continuing traditional

\footnotetext{
27 The values for the varying coefficients models (2) are almost identical.

28 We follow Wakefield (2007), who discusses the problem of spatial modeling in a study on disease mapping. He argues, that the inclusion of further spatial effects could seriously cover substantial underlying effects and that the problem could only be solved by using individual data, which are obviously not available.

${ }^{29}$ See Brustein (1996: 85-89).
} 
way of life and, at the same time, the increasing involvement in and dependence on the market. This discrepancy is most painful for the middle peasantry. Authors like Hobsbawm (1973), Moore (1966), and Linz (1976), indeed, considered the role of the German peasantry as crucial for the understanding of the take-over of the Nazis and the abolishment of democracy. According to Linz, the rural stratum most susceptible to fascism are so-called "proprietors of farmer-capitalist agricultural enterprises" (Linz 1976: 375). They are highly market-oriented and therefore politically sensitive to economic crises and government policies. As long as they rely on non-family hired workforce, they are also hostile to socialist and communist parties. Contrary to consumptive or subsistence peasants, they have no loyalties to traditional parties: “The political alternatives likely to appeal to these strata are: various centrist and undefined forces; all kinds of liberalism at the end of the century; conservative-nationalistic, anticlerical-conservative, peasant ideologies of various kinds; nontraditional 'democratic' conservative authoritarianism; Bonapartism, Boulangism, and the like; and finally, in the thirties, fascism.” (Linz 1976: 376).

In his comparative analysis of agrarian movements in Europe 1850-1940, Urwin (1980) demonstrates in detail the "interconnection between agrarian structure, socio-economic change and political activity” (Urwin 1980: 12). Urwin refers to the success of the Nazis in Bavaria, Hessie, to Rexism in Belgium (see also Brustein 1988) and the Quisling in Norway as well as to diverse agro-fascist movements in Eastern Europe (Urwin 1980: 182). The antisystem potential of peasants was always unleashed “...whenever the agrarian parties failed to react to the current economic programs of the peasantry” (Urwin 1980: 182).

However, this processes not only differed so dramatically over countries, but also within countries we observe the construction of quite different political spaces. We argued for the first time that the effectiveness of space construction should be visible when comparing political territories of a federation (holding their own elections) and of electoral districts therein. As Cox (1997: 38) stated, "electoral laws and rules regulate how parties nominate candidates, how citizens vote and how those votes are counted". This forceful mechanism affects expectation formation both at the level of the elites as well as the voters - and should therefore be identifiable as a distinct political space. Actually, we not only provide a scale for the geographical variation of these spaces, we also have shown that accounting for these spaces absorbs spatial dependencies in both substantial as well as statistical manner.

Finally, we emphasize that this is the first time that generalized additive models (GAM) have been used in the context of electoral aggregate data analysis, thus allowing us to identify nonlinear relationships. We selected this statistical strategy because we consider it an important step for uncovering spatial and social peculiarities of voter transitions. 


\section{References}

Beck, Nathaniel, and Simon Jackman. 1998. Beyond Linearity by Default: Generalized Additive Models. American Journal of Political Science 42: 596-627.

Belitz, Christiane, Andreas Brezger, Thomas Kneib, and Stefan Lang. 2009. BayesX. Software for Bayesian Inference in Structured Additive Regression Models. Version 2.0.1. Methodology Manual, Munich, Germany.

Brustein, William, and Jürgen W. Falter. 1994. “The Sociology of Nazism: An Interest-Based Account” Rationality and Society. 6:369-399.

Brustein, William. 1988. “The Political Geography of Belgian Fascism: The Case of Rexism” American Sociological Review. 53:69-80.

Brustein, William, 1996: The Logic of Evil. The Social Origins of the Nazi Party, 1925-1933. New Haven, London: Yale University Press.

Burnham, Walter D. 1972. "Political Immunization and Political Confessionalism: The United States and Weimar Germany” The Journal of Interdisciplinary History. 3:1-30.

Childers, Thomas. 1976. “The Social Bases of the National Socialist Vote” Journal of Contemporary History. 11:17-42.

Craven, Peter and Grace Wahba. 1979. “Smoothing Noisy Data with Spline Functions” Numerische Mathematik. 31:377-403.

Corni, Gustavo. 1990: Hitler and the Peasants. New York: Berg.

Cox. Gary W. 1997. Making Votes Count. Strategic Coordination in the World's Electoral Systems. Cambridge: Cambridge University Press.

Eilers, Paul H. C. and Brian D. Marx. 1996. "Flexible Smoothing with B-splines and Penalties” Statistical Science. 11:89-102.

Fahrmeir, Ludwig, Thomas Kneib, and Stefan Lang. 2004. "Penalized Structured Additive Regression for Space-Time Data: A Bayesian perspective” Statistica Sinica. 14:715-745.

Falter, Jürgen W. 1980: “Wählerbewegungen zur NSDAP 1924-1933. Methodische Probleme - Abgesicherte Erkenntnisse - Offene Fragen” Pp. 152-202 in Wählerbewegungen in der Europäischen Geschichte, edited by O. Büsch. Berlin: Colloquium Verlag.

-----.1981. "Radicalization of the Middle Classes or Mobilization of the Unpolitical?: The Theories of Seymour M. Lipset and Reinhard Bendix on the Electoral Support of the NSDAP in the Light of Recent Research” Social Science Information. 20:389-430.

-----. 1986. “Der Aufstieg der NSDAP in Franken bei den Reichstagswahlen 1924-1933. Ein Vergleich mit dem Reich unter besonderer Berücksichtigung landwirtschaftlicher Einflußfaktoren” German Studies Review. 9:319-359.

-----. 1990. “The First German Volkspartei: The Social Foundations of the NSDAP” Pp. 5381 in Elections, parties and political traditions. Social foundations of German parties and party systems 1867 - 1987, edited by K. Rohe. Munich, Germany: Berg. 
-----. 1991. Hitlers Wähler, Munich, Germany: Beck.

Falter, Jürgen W. and Wolf D. Gruner. 1981. "Minor and Major Flaws of a Widely Used Data Set: The ICPSR” German Weimar Republik Data 1919-1933" under Scrutiny" Historical Social Research. 20:4-26.

Flint, Colin. 1998. "Forming Electorates, Forging Spaces: The Nazi Party Vote and the Social Construction of Space” American Behavioral Scientist. 41 (9): 1282-1303.

Flint, Colin. 2001. “A TimeSpace for Electoral Geography: Economic Restructuring, Political Agency and the Rise of the Nazi Party” Political Geography 20 (3): 301-329.

Friedrich, Carl J. 1937. “The Agricultural Basis of Emotional Nationalism” Public Opinion Quarterly. 1:50-61.

Geiger, Theodor. 1932. Die Soziale Schichtung des Deutschen Volkes. Soziographischer Versuch auf Statistischer Grundlage, Stuttgart, Germany: Verlag Ferdinand Enke.

Gessner, Dieter. 1981. “The dilemma of German Agriculture during the Weimar Republic” Pp. 134-153, in Social Change and Political Development in Weimar Germany, edited by Richard Bessel. London: Croom Helm.

Hastie, Trevor and Robert Tibshirani. 1986. "Generalized Additive Models” Statistical Science. 1:297-318.

------. 1993. “Varying-coefficient Models” Journal of the Royal Statistical Society. Series B. 55:757-796.

Heberle, Rudolf. 1945. From Democracy to Nazism. A Regional Case Study on Political Parties in Germany, Baton Rouge, LA: Louisiana State University Press.

------. [1934] 1963. Landbevölkerung und Nationalsozialismus. Eine Soziologische Untersuchung der Politischen Willensbildung in Schleswig-Holstein 1918 bis 1932, Stuttgart, Germany: Deutsche Verlags-Anstalt.

Huntington, Samuel P. 1968. Political Order in Changing Societies New Haven, CT: Yale University Press.

Hobsbawm, Eric J. 1973. "Peasants and Politics" Journal of Peasant Studies. 1:3-22.

James, Harold. 1986. The German Slump: Politics and Economics, 1924-1936, Oxford, UK: Clarendon Press.

Jatzlauk, Manfred. 1986. "Statistisches zur sozialökonomischen Entwicklung der Mittelbauern in Deutschland während der Zwischenkriegszeit“ WZ Rostock. 35:27-33.

Jatzlauk, Manfred. 1995. “Soziale Zusammensetzung und wirtschaftliche Lage der Landarbeiterschaft in der Weimarer Republik (1919-1933)“ Agrargeschichte. 25:107122.

Jones, Larry E. 1986. "Crisis and Realignment. Agrarian Splinter Parties in the Late Weimar Republic, 1928-1933" Pp. 198-232, in Peasants and Lords in Modern Germany. Recent Studies in Agricultural History, edited by Robert G. Moeller. Boston: Allen \& Unwin. 
Keele, Luke. 2008. Semiparametric Regression for the Social Sciences, Chichester, UK: Wiley.

King, Gary, Ori Rosen, Martin A. Tanner and Alexander F. Wagner. 2008. "Ordinary Economic Voting Behavior in the Extraordinary Election of Adolf Hitler” The Journal of Economic History. 68:951-996.

Kuehn, Ingolf. 2007. "Incorporating Spatial Autocorrelation May Invert Observed Patterns” Diversity and Distributions. 13: 66-69.

Linz, Juan. 1976. "Patterns of Land Tenure, Division of Labor, and Voting Behavior in Europe“ Comparative Politics. 8: 365-430.

Lipset, Seymour D. 1950. Agrarian Socialism: The Cooperative Commonwealth Federation in Saskatchewan. A Study in Political Sociology, Berkeley, CA: University of California Press.

-----. 1960. Political Man: the Social Bases of Politics, Garden City, NY: Doubleday.

Lipset, Seymour D. and Stein Rokkan. 1967. Party Systems and Voter Alignments: Cross National Perspectives, New York: Free Press.

Loomis, Charles P. and J. A. Beegle. 1946. "The Spread of German Nazism in Rural Areas” American Sociological Review. 11:724-734.

Moore, Barrington. 1966. Social Origins of Dictatorship and Democracy: Lord and Peasant in the Making of the Modern World, Boston, MA: Beacon Press.

O'Loughlin, John. 2002. “The Electoral Geography of Weimar Germany: Exploratory Spatial Data Analyses (ESDA) of Protestant Support for the Nazi Party” Political Analysis. 10:217-243.

O'Loughlin, John, Colin Flint, and Luc Anselin. 1994. “The Geography of the Nazi Vote: Context, Confession, and Class in the Reichstag Election of 1930" Annals of the Association of American Geographers. 84:351-380.

Rose, Richard and Thomas T. Mackie. 1988. "Do Parties Persist or Fail? The Big Trade-off Facing Organizations” Pp. 533-558, in When parties fail. Emerging alternative organizations, edited by K. Lawson. Princeton, NJ: Princeton University Press.

Ruppert, David, Matt P. Wand, and Raymond J. Carroll. 2003. Semiparametric Regression, Cambridge, UK: Cambridge University Press.

Skocpol, Theda. 1979. States and Social Revolutions, Cambridge, UK: Cambridge University Press.

Shively, W. P. 1972. "Party Identification, Party Choice, and Voting Stability: The Weimar Case” The American Political Science Review. 66:1203-1225.

Statistik des Deutschen Reichs. 1929. Volks-, Berufs- und Betriebszahlung vom 16. Juni 1925: Landwirtschaftliche Betriebszahlung. Die Hauptergebnisse in den Kleineren Verwaltungsbezirken der Länder des Deutschen Reichs. Band 412 I, Berlin, Germany. 
Taylor, Michael E. 1988. Rationality and Revolution, Cambridge, UK: Cambridge University Press.

Urwin, Derek W. 1980. From Ploughshare To Ballotbox. The Politics of Agrarian Defence in Europe, Oslo, Norway: Universitetsforlaget.

Wakefield, Jon. 2007. "Disease mapping and spatial regression with count data” Biostatistic 8: 158-183.

Waldman, Loren K. 1973. Models of mass movements. The Case of the Nazis, Chicago, IL: Ph.D. dissertation, University of Chicago, Chicago, IL.

Wehler, Hans-Ulrich. 2008. Deutsche Gesellschaftsgeschichte. Vom Beginn des Ersten Weltkrieges bis zur Gründung der beiden deutschen Staaten 1914-1949. Vol. 4, Munich, Germany: Beck.

Wolf, Eric R. 1969. Peasant Wars of the Twentieth Century, New York: Harper \& Row. 


\section{Appendix}

\section{A. Data and Data Description}

Table 5: Variables and their Operationalization

\begin{tabular}{|c|c|c|c|}
\hline Variable & Source & Base population & $\begin{array}{c}\text { Minimal level of } \\
\text { aggregation }\end{array}$ \\
\hline $\begin{array}{l}\text { Election Results } \\
\text { NSDAP }\end{array}$ & $\begin{array}{l}\text { Different Sources } \\
\text { (ZA8013) }\end{array}$ & $\begin{array}{l}\text { Eligible Voters for this } \\
\text { Election }\end{array}$ & $\begin{array}{l}\text { County } \\
\text { (Kreise) }\end{array}$ \\
\hline Region & $\begin{array}{l}\text { Political Structure of } \\
\text { the Weimar Republic }\end{array}$ & - & $\begin{array}{c}\text { Province, } \\
\text { Federal State }\end{array}$ \\
\hline $\begin{array}{c}\text { Members of Protestant } \\
\text { Churches }\end{array}$ & $\begin{array}{l}\text { Different Sources } \\
\text { (ZA8013) }\end{array}$ & $\begin{array}{c}\text { Resident Population } \\
1925\end{array}$ & Municipality \\
\hline Workers Total & Census 1925 & $\begin{array}{c}\text { Resident Population } \\
1925\end{array}$ & Municipality \\
\hline $\begin{array}{l}\text { Workers in Industry } \\
\text { and Handcraft }\end{array}$ & Census 1925 & $\begin{array}{c}\text { Resident Population } \\
1925\end{array}$ & Municipality \\
\hline Unemployed 1933 & Census 1933 & $\begin{array}{c}\text { Resident Population } \\
1933\end{array}$ & Municipality \\
\hline Urbanization & $\begin{array}{l}\text { Reichswohnzählung } \\
\text { 1927, Census } 1925\end{array}$ & $\begin{array}{c}\text { Resident Population } \\
1925\end{array}$ & $\begin{array}{c}\text { Municipalities } \\
\text { with more than } \\
5000 \\
\text { Inhabitants }\end{array}$ \\
\hline $\begin{array}{l}\text { Parcel Farmers } \\
\quad(0-2 \text { ha })\end{array}$ & Census 1925 & $\begin{array}{c}\text { Resident Population } \\
1925\end{array}$ & County \\
\hline $\begin{array}{l}\text { Small Farmers } \\
\quad(2-5 \text { ha })\end{array}$ & Census 1925 & $\begin{array}{c}\text { Resident Population } \\
1925\end{array}$ & County \\
\hline $\begin{array}{l}\text { Middle Farmers } \\
\qquad(5-20 \text { ha })\end{array}$ & Census 1925 & $\begin{array}{c}\text { Resident Population } \\
1925 \\
\end{array}$ & County \\
\hline $\begin{array}{l}\text { Large Farmers } \\
(20-100 \text { ha })\end{array}$ & Census 1925 & $\begin{array}{c}\text { Resident Population } \\
1925 \\
\end{array}$ & County \\
\hline $\begin{array}{l}\text { Large Estate Farmers } \\
\qquad(100+\text { ha })\end{array}$ & Census 1925 & $\begin{array}{c}\text { Resident Population } \\
1925\end{array}$ & County \\
\hline
\end{tabular}


Table 6: Regional Indicator Variable: Assigned Regional Code and Corresponding Association of Electoral Districts (Wahlkreisverband)

\begin{tabular}{|c|c|c|}
\hline $\begin{array}{l}\text { Regional- } \\
\text { Code }\end{array}$ & $\begin{array}{l}\text { Association of } \\
\text { Electoral Districts }\end{array}$ & $\begin{array}{l}\text { Provinces of Prussia or Regions / States of the Weimar } \\
\text { Republic }\end{array}$ \\
\hline 1 & I & Province East Prussia \\
\hline 3 & II, III & Province Brandenburg, City Berlin \\
\hline 4 & IV & Province Pomerania \\
\hline 5 & III & Province Borderland Posen \\
\hline 6 & $\mathrm{~V}$ & Province Lower Silesia \\
\hline 7 & $\mathrm{~V},(\mathrm{VI})^{1}$ & Province Upper Silesia \\
\hline 8 & VI & Province Saxony \\
\hline 9 & $(\mathrm{IV})^{1}, \mathrm{VII}$ & $\begin{array}{l}\text { Province Schleswig-Holstein, State Lübeck, State } \\
\text { Oldenburg: Part Lübeck }\end{array}$ \\
\hline 10 & $(\mathrm{VII})^{1}, \mathrm{VIII}$ & Province Hanover, State Hamburg, State Bremen \\
\hline 11 & IX & Province Westphalia \\
\hline 12 & $(\mathrm{VI})^{1},(\mathrm{IX})^{1}, \mathrm{X}$ & Province Hessen-Nassau, State Waldeck \\
\hline 13 & XI, XII & Rhine-province, State Oldenburg: Part Birkenfeld \\
\hline 15 & XIII & Bavaria - South Bavaria \\
\hline 16 & XIII, XIV & Bavaria - North Bavaria \\
\hline 17 & XIV & Bavaria - Pfalz \\
\hline 18 & $\mathrm{XV}$ & State Saxony \\
\hline 19 & XVI & State Württemberg, Province Hohenzollern \\
\hline 20 & XVI & State Baden \\
\hline 21 & VI & State Thuringia \\
\hline 22 & $\mathrm{X}$ & State Hessen \\
\hline 24 & IV & State Mecklenburg-Schwerin, State Mecklenburg-Strelitz \\
\hline 25 & VIII & State Oldenburg without the Parts Lübeck and Birkenfeld \\
\hline 26 & VI, VIII, IX & $\begin{array}{l}\text { State Braunschweig, State Anhalt, State Lippe, State } \\
\text { Schaumburg-Lippe }\end{array}$ \\
\hline
\end{tabular}

Association of electoral districts in brackets covers parts of an Association of electoral districts which belong to the respective region but represent only minor parts of the constructed region and the Association of electoral districts. 
Election May 24

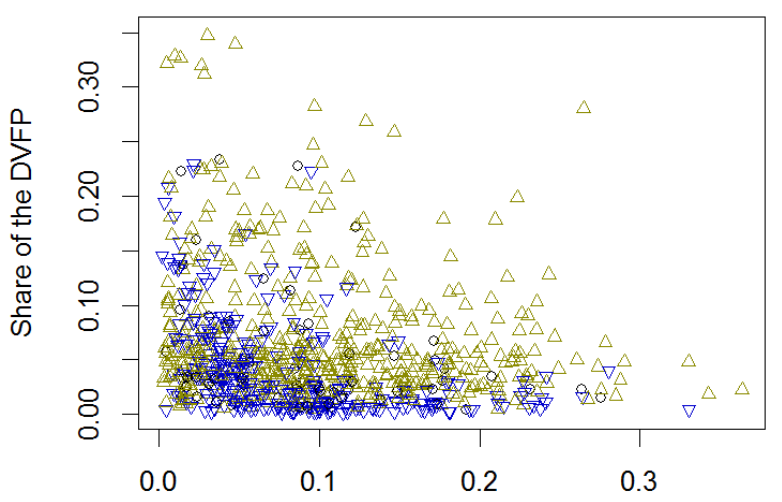

Election Sept 30

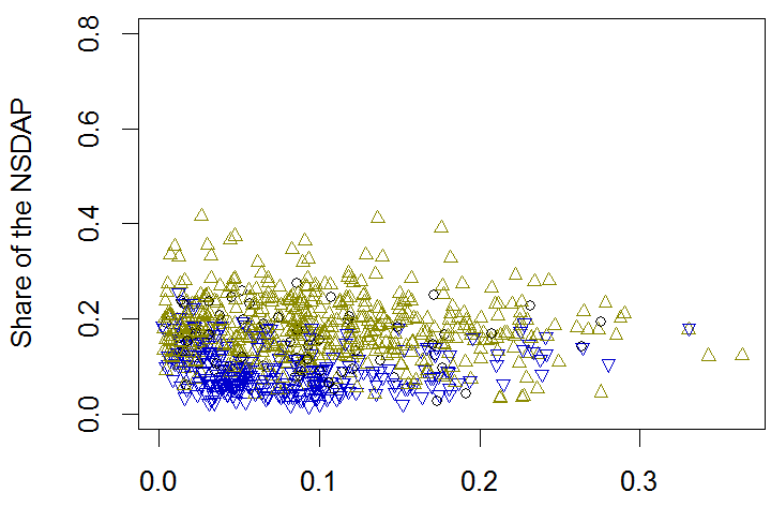

Election Nov 32

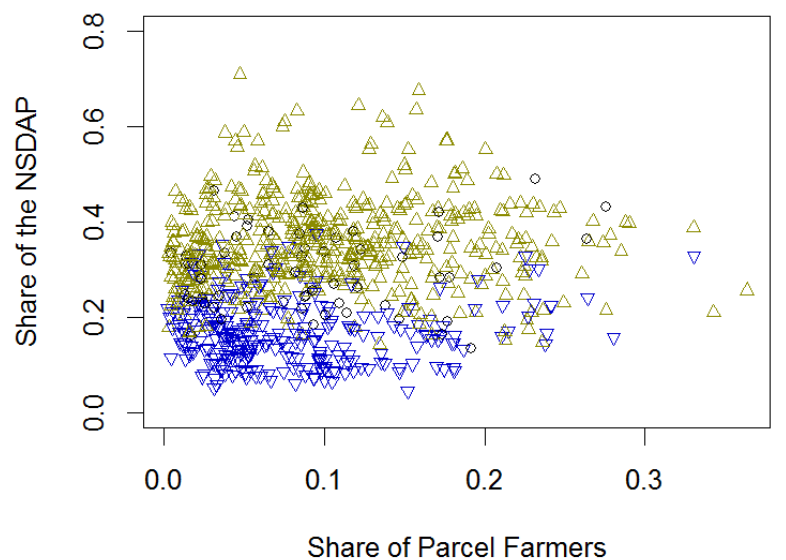

Election May 28

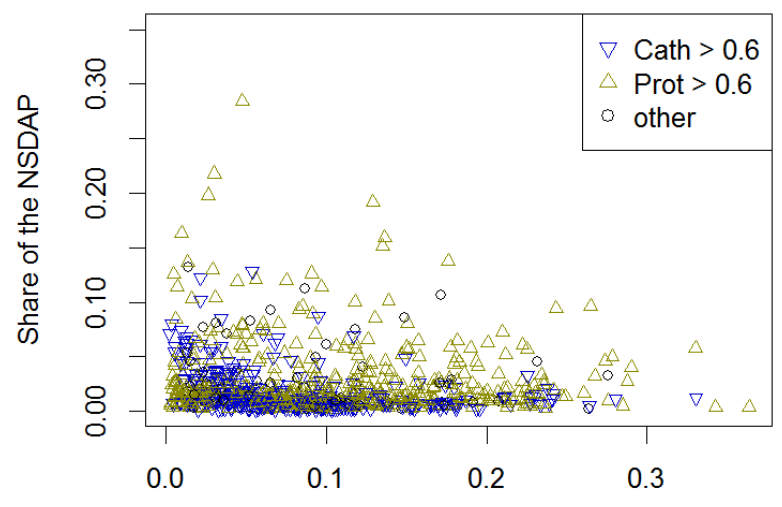

Election Jul 32

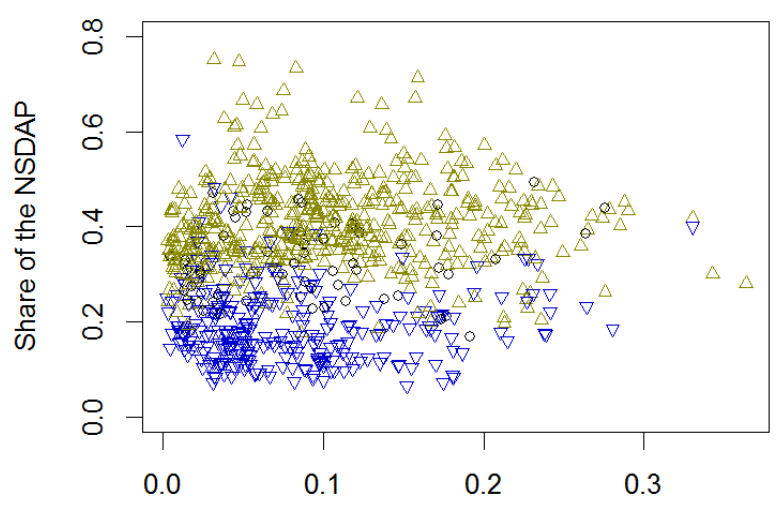

Election Mar 33

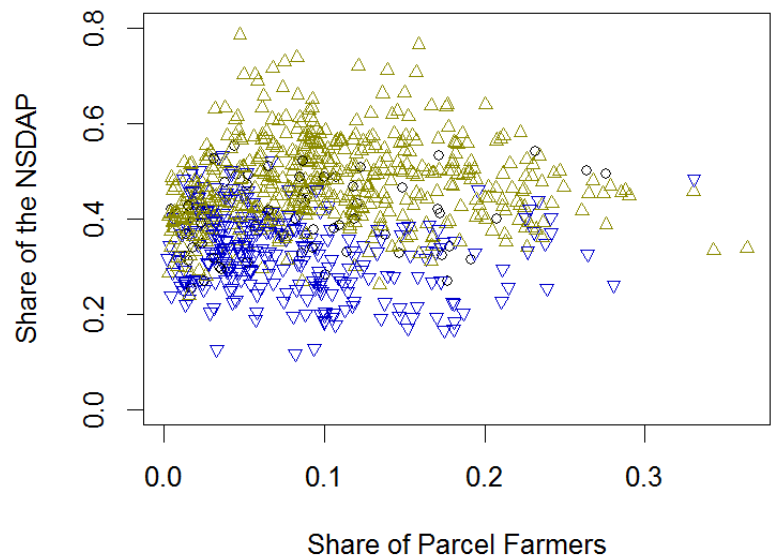

Figure 8: Share of Parcel Farmers (0-2 ha) and Election Result of the NSDAP 


\section{Election May 24}

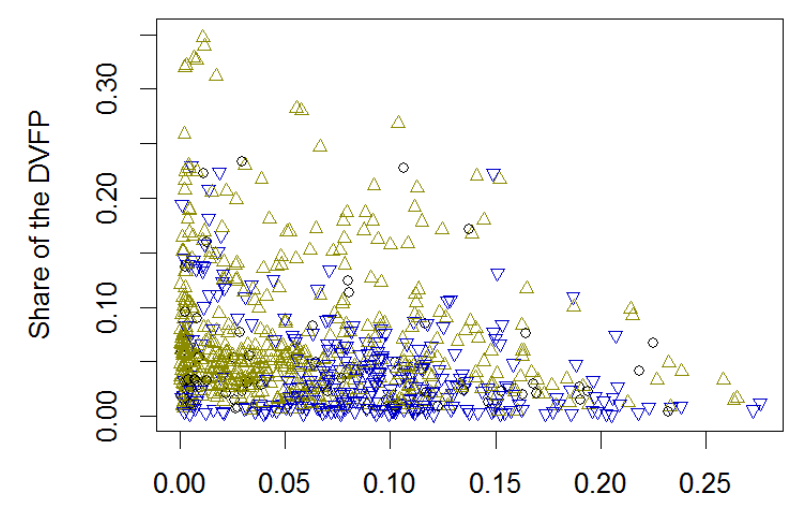

Election Sept 30

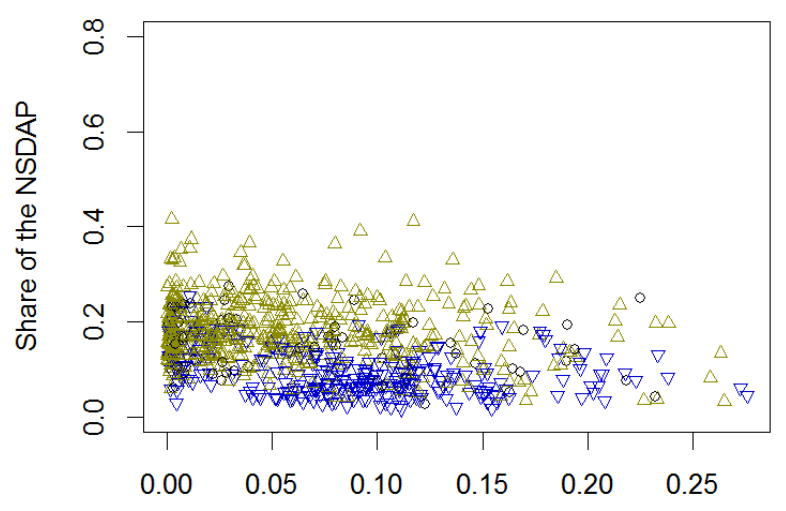

Election Nov 32

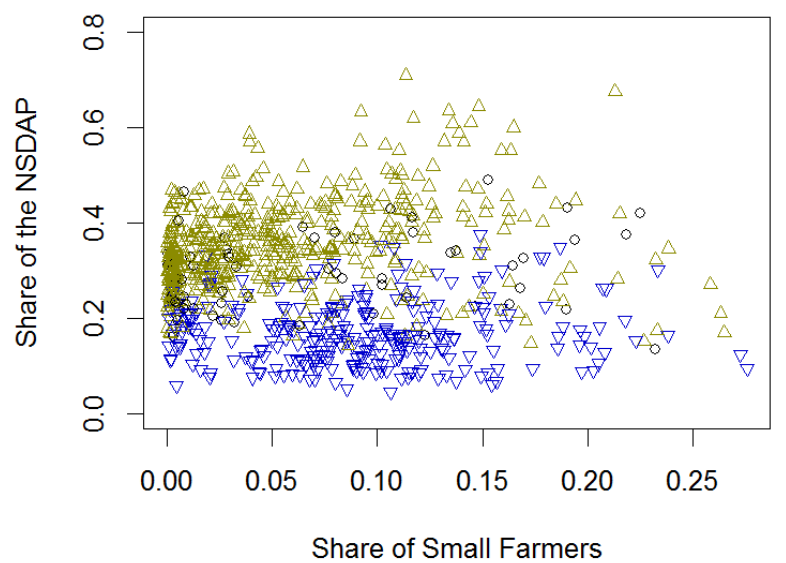

Election May 28

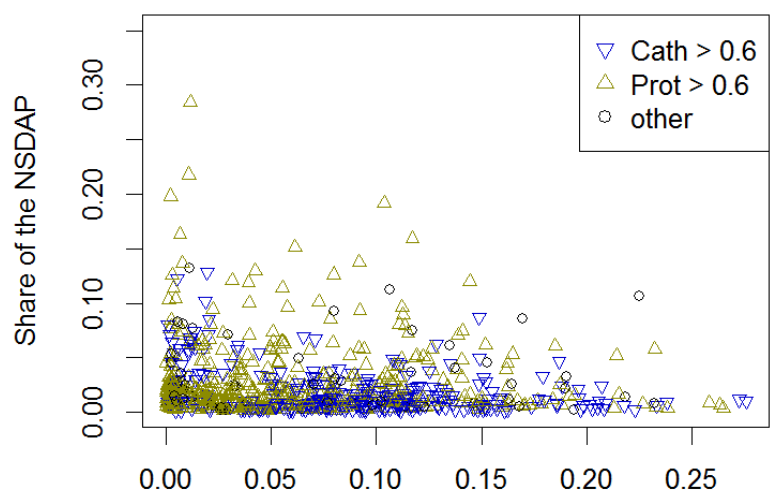

Election Jul 32

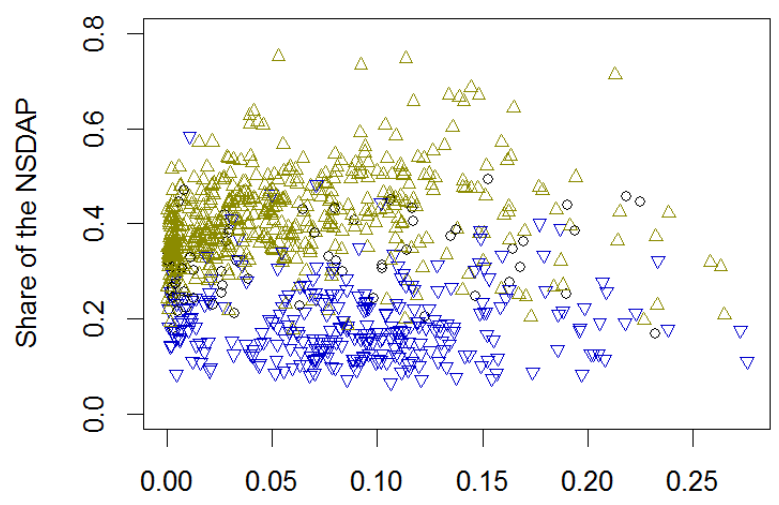

Election Mar 33

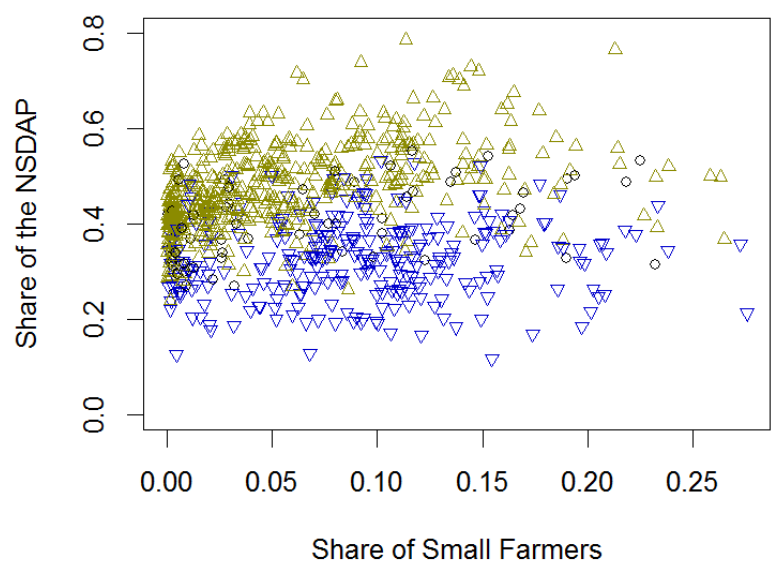

Figure 9: Share of Small Farmers (2-5 ha) and Election Result of the NSDAP 
Election May 24

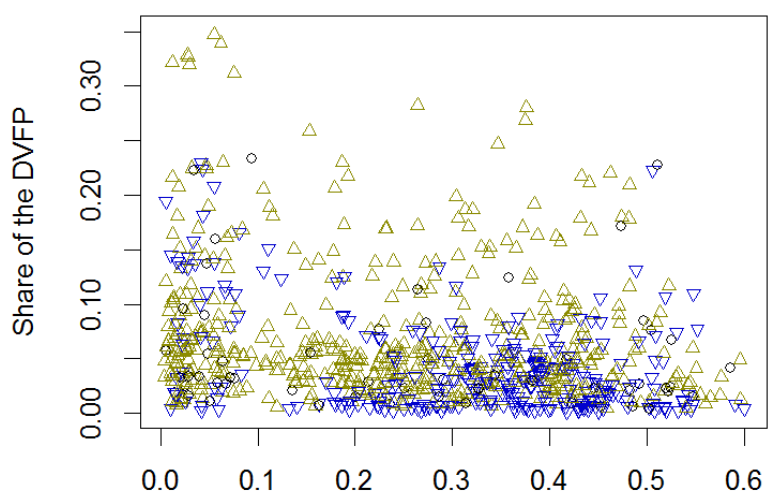

Election Sept 30

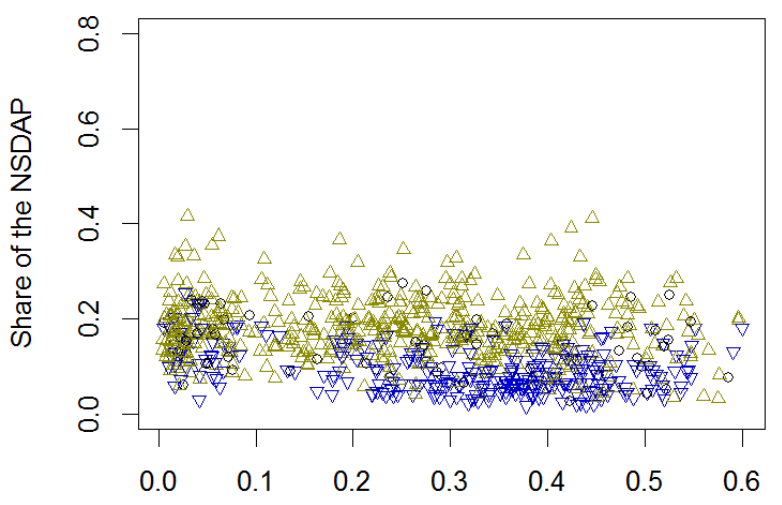

Election Nov 32

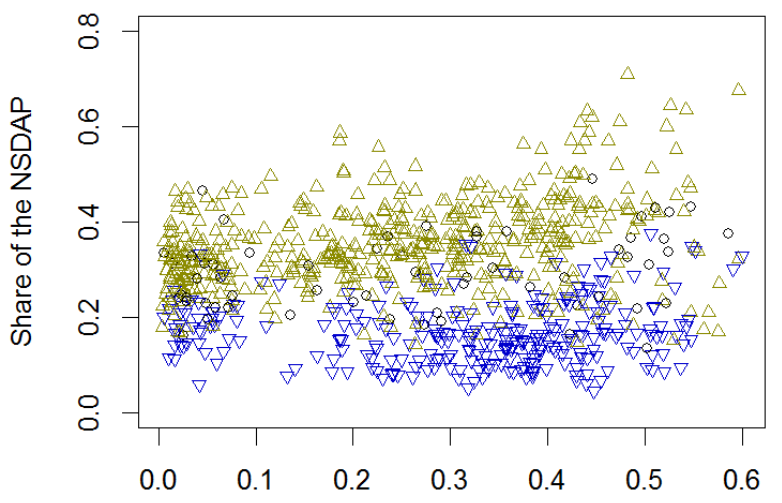

Share of the Composite Variable (0-20ha)
Election May 28

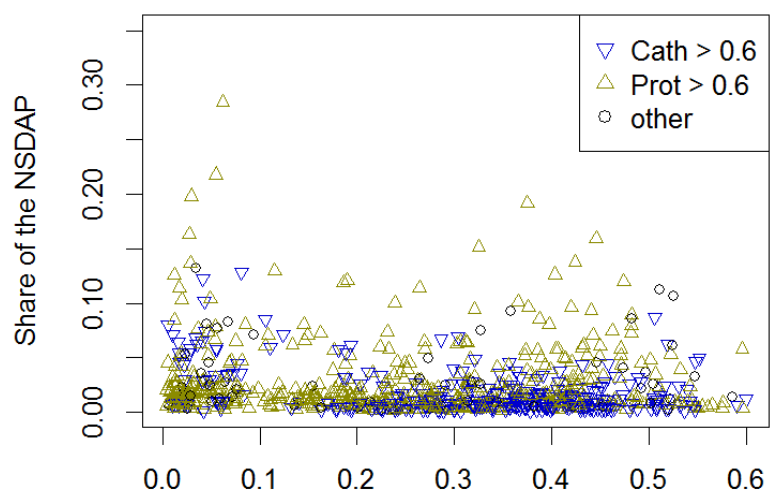

Election Jul 32

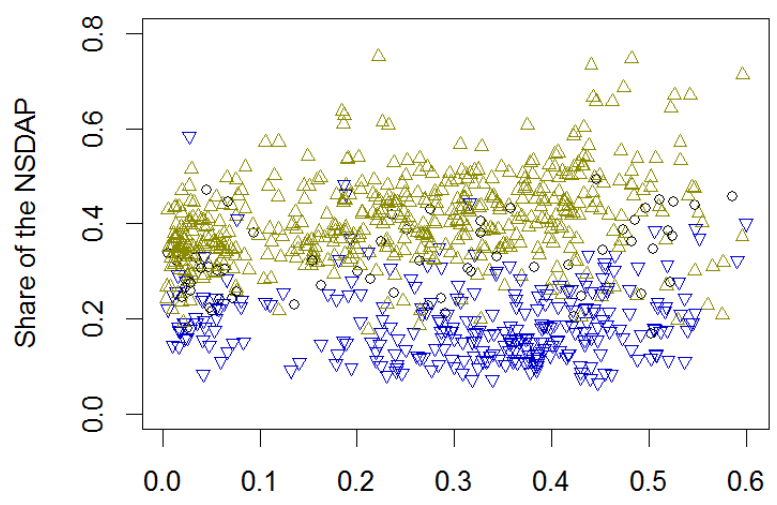

\section{Election Mar 33}

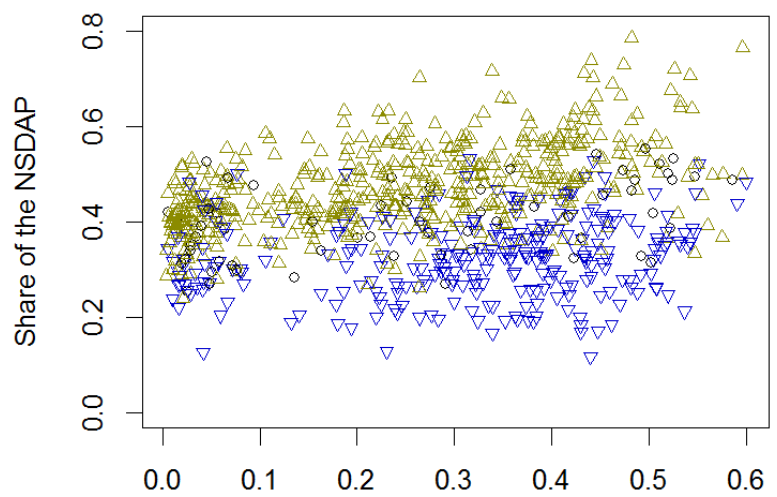

Share of the Composite Variable (0-20ha)

Figure 10: Share of Parcel, Small and Middle Farmers (Composite Variable: 0-20 ha) and Election Result of the NSDAP 


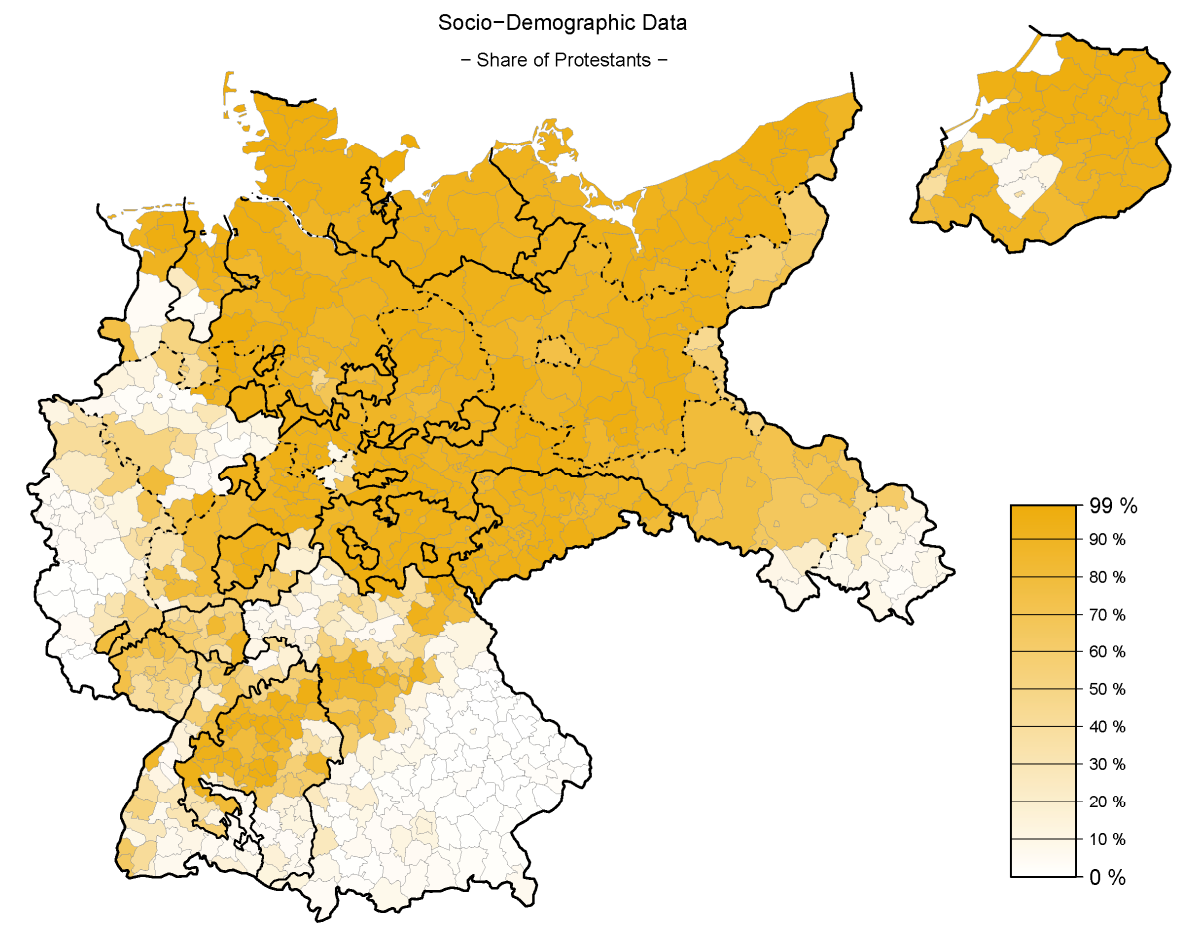

Figure 11: Percentage of Protestants in Counties, Sources: Statistik des Deutschen Reichs (1929) and Census 1925

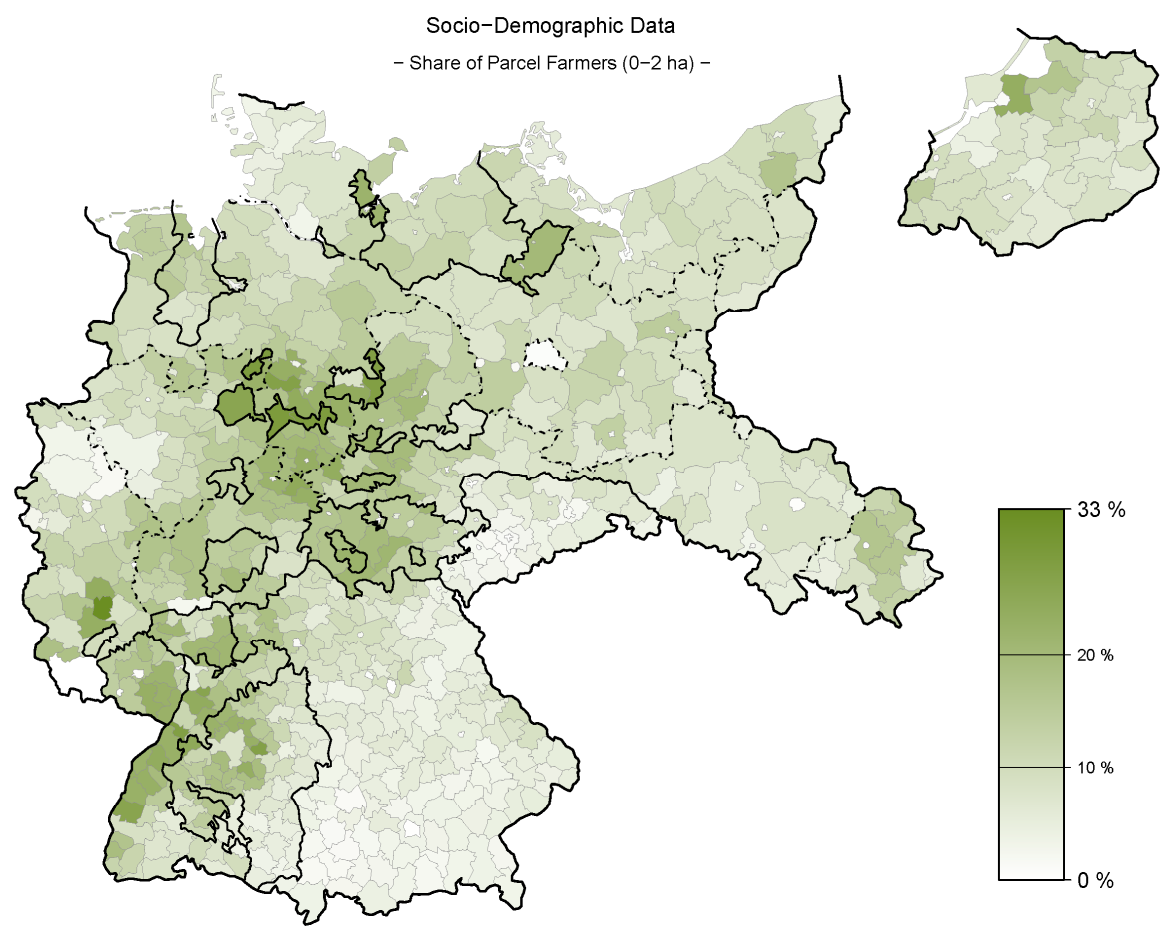

Figure 12: Workforce in Parcel Farms, Sources: Statistik des Deutschen Reichs (1929) and Census 1925 


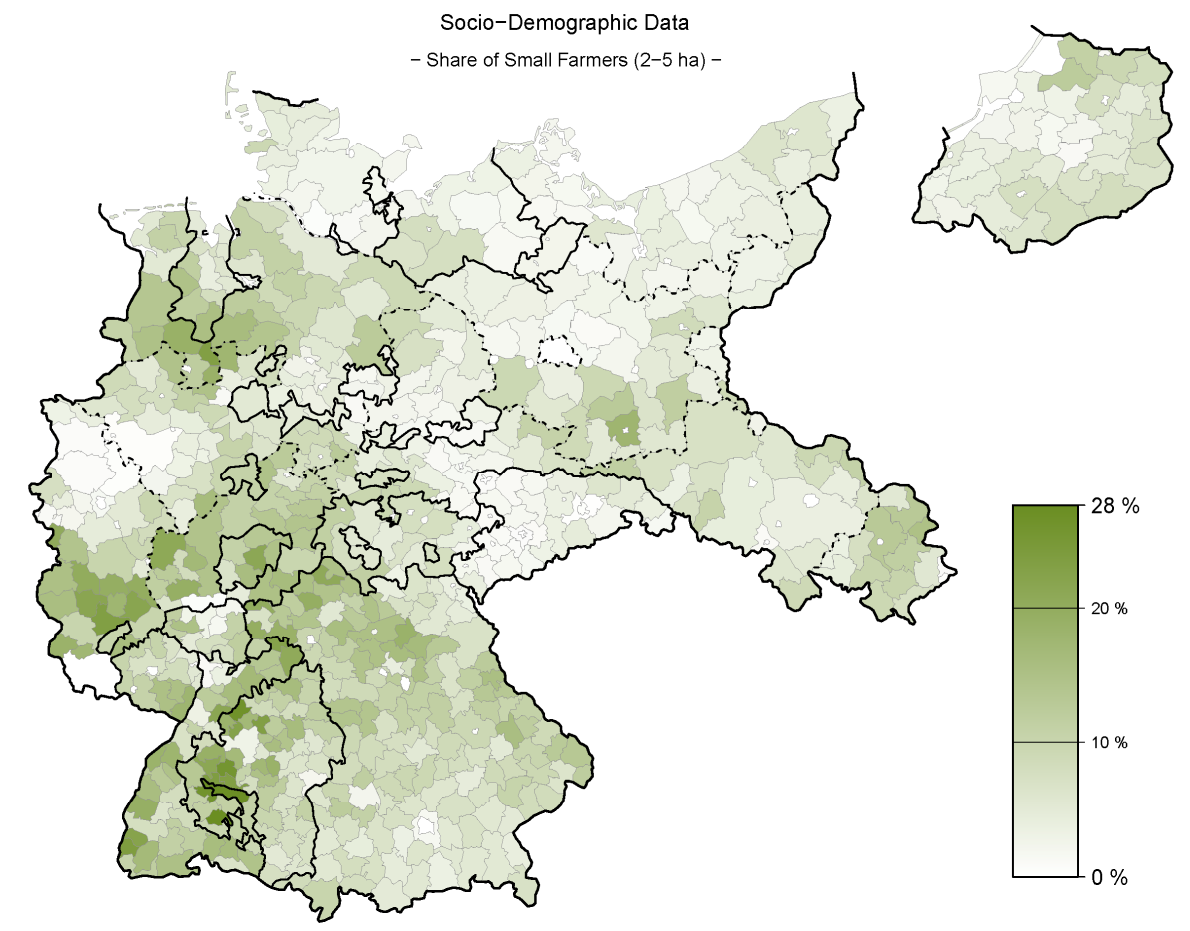

Figure 13: Workforce in Small Farms, Sources: Statistik des Deutschen Reichs (1929) and Census 1925

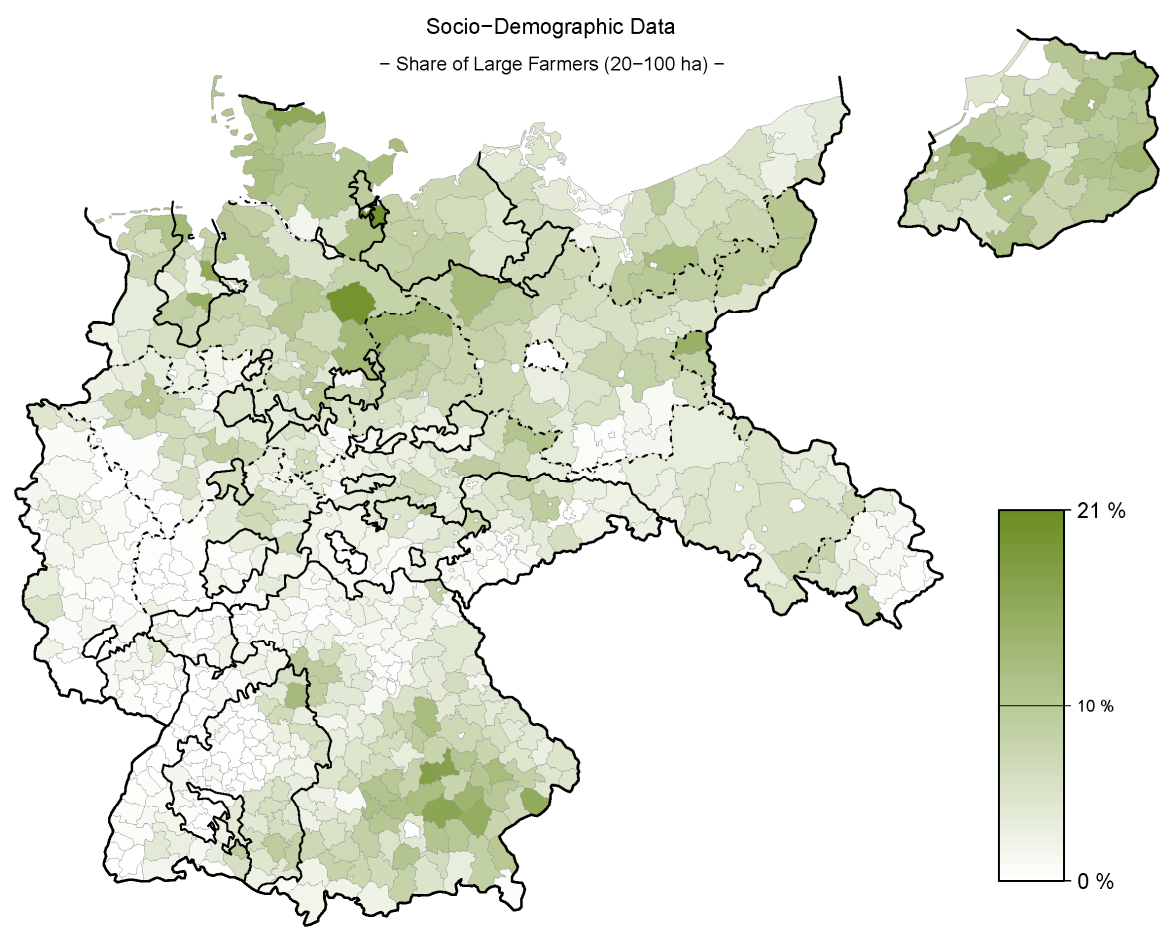

Figure 14: Workforce in Large Farms, Sources: Statistik des Deutschen Reichs (1929) and Census 1925 


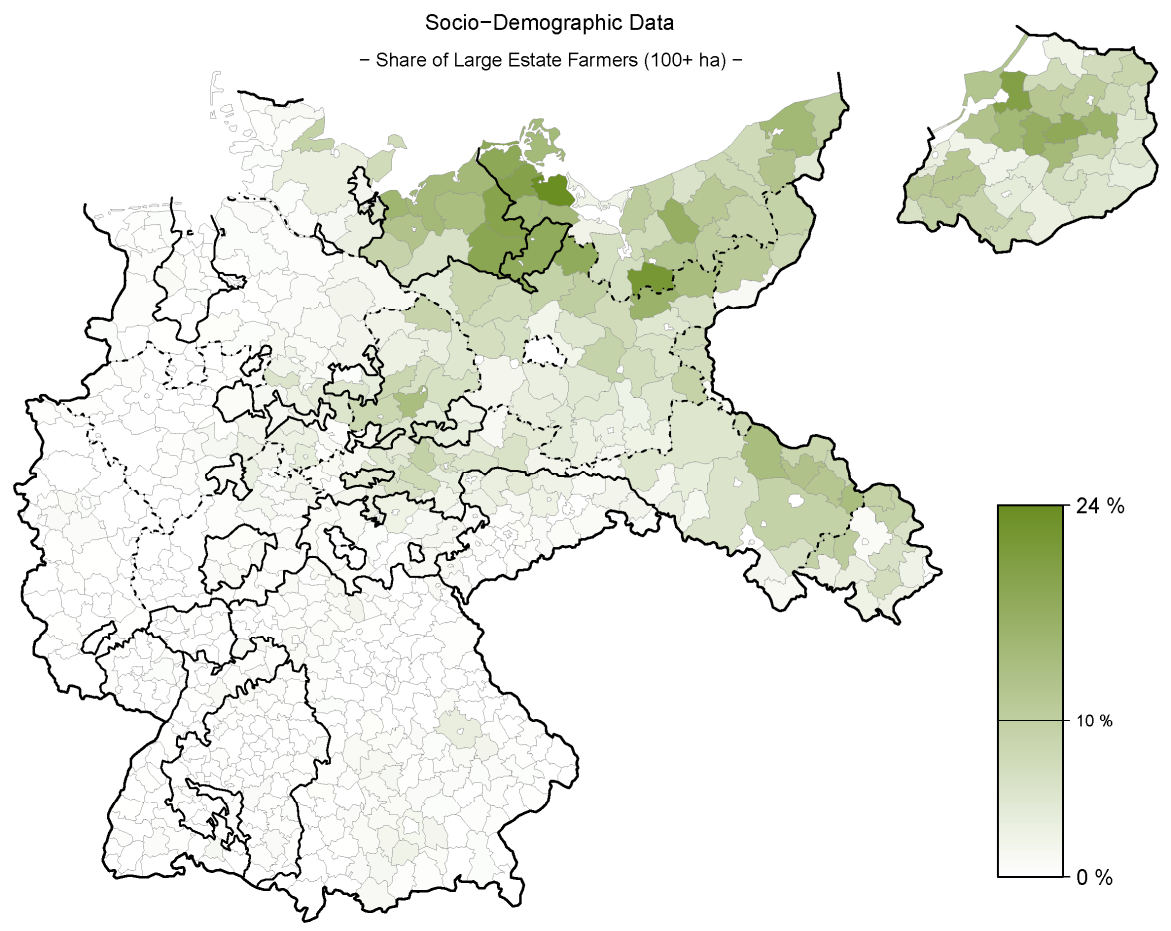

Figure 15: Workforce in Large Estates, Sources: Statistik des Deutschen Reichs (1929) and Census 1925 


\section{B. Model Results}

Table 7: Model Results: Point Estimators, Model 1a, see Table 5 for a Description of the Regions

\begin{tabular}{|c|c|c|c|c|c|c|c|}
\hline Regional-Code & May 24 & Dec 24 & May 28 & Sept 30 & Jul 32 & Nov 32 & Mar 33 \\
\hline 1 & $0^{1}$ & $0^{1}$ & $0^{1}$ & $0^{1}$ & $0^{1}$ & $0^{1}$ & $0^{1}$ \\
\hline 3 & -0.720 & -0.824 & 0.768 & 0.084 & -0.019 & 0.110 & -0.072 \\
\hline 4 & -0.239 & -0.448 & 0.652 & 0.021 & -0.035 & 0.102 & -0.070 \\
\hline 5 & 0.836 & 0.800 & -0.125 & -0.081 & 0.317 & 0.445 & 0.213 \\
\hline 6 & -0.778 & -0.917 & 0.662 & 0.627 & 0.516 & 0.604 & 0.382 \\
\hline 7 & -0.093 & -0.067 & 1.321 & 0.070 & 0.692 & 0.773 & 0.609 \\
\hline 8 & -0.218 & -0.287 & 1.291 & 0.145 & 0.139 & 0.147 & -0.020 \\
\hline 9 & -0.315 & -0.850 & 1.361 & 0.275 & 0.299 & 0.411 & 0.053 \\
\hline 10 & -0.282 & -0.475 & 1.425 & 0.158 & 0.083 & 0.131 & -0.098 \\
\hline 11 & -0.754 & -0.993 & 0.989 & 0.031 & 0.023 & 0.088 & -0.013 \\
\hline 12 & -0.225 & -0.504 & 1.614 & 0.299 & 0.334 & 0.501 & 0.217 \\
\hline 13 & -0.514 & -0.976 & 1.439 & 0.504 & 0.418 & 0.439 & 0.292 \\
\hline 15 & 1.786 & 1.349 & 3.119 & 0.779 & 0.542 & 0.611 & 0.500 \\
\hline 16 & 1.380 & 0.990 & 2.840 & 0.609 & 0.404 & 0.497 & 0.242 \\
\hline 17 & -0.061 & -0.489 & 2.290 & 0.558 & 0.637 & 0.800 & 0.397 \\
\hline 18 & -0.350 & -0.703 & 1.381 & 0.132 & 0.150 & 0.238 & 0.012 \\
\hline 19 & -0.474 & -0.616 & 0.923 & -0.572 & -0.393 & -0.379 & -0.208 \\
\hline 20 & -0.091 & -0.355 & 1.572 & 0.452 & 0.449 & 0.503 & 0.364 \\
\hline 21 & 0.194 & -0.021 & 1.613 & 0.059 & 0.050 & 0.058 & -0.102 \\
\hline 22 & -0.873 & -1.122 & 0.872 & 0.115 & 0.376 & 0.465 & 0.205 \\
\hline 24 & 0.910 & 0.739 & 0.870 & -0.162 & -0.063 & -0.035 & -0.240 \\
\hline 25 & -0.351 & -0.350 & 2.432 & 0.440 & 0.162 & 0.130 & -0.249 \\
\hline 26 & -0.009 & -0.242 & 2.025 & 0.366 & 0.301 & 0.406 & 0.052 \\
\hline Parameter & May 24 & Dec 24 & May 28 & Sept 30 & Jul 32 & Nov 32 & Mar 33 \\
\hline Intercept & -3.210 & -3.765 & -5.605 & -2.070 & -0.995 & -1.295 & -0.463 \\
\hline $\begin{array}{l}\text { Middle Farmers } \\
\text { ("linear") }^{2}\end{array}$ & -1.265 & -1.159 & -2.104 & 0.258 & 1.544 & 1.817 & 1.696 \\
\hline
\end{tabular}


Spatial Effect: Regional Indicator Variable, Election May 24 min: -0.82 , max: 1.84 , centered around: -0.05

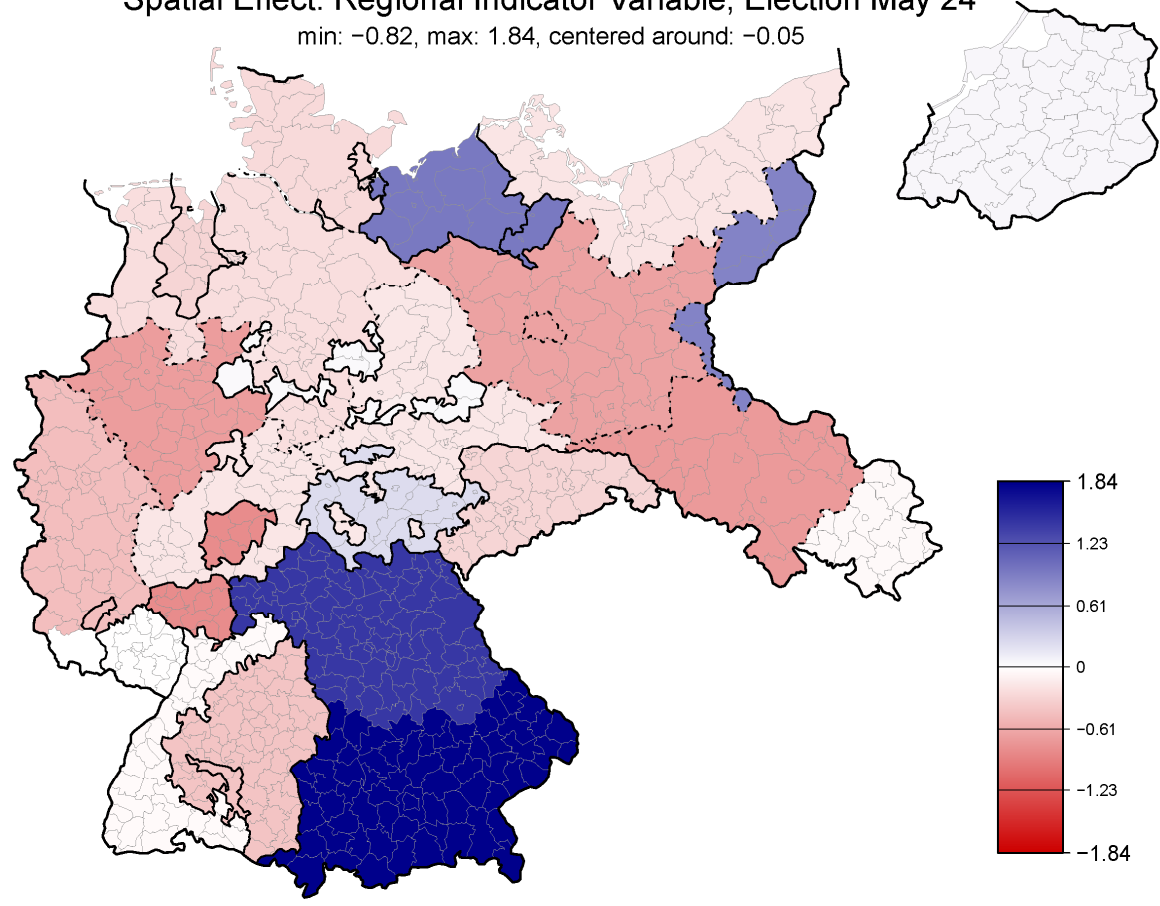

Figure 16: Regional Indicator Variable: Estimated Spatial Effect, Election May 1924, Centered Around Average Effect, Identical Scale Used for 1924 - 1928 Elections

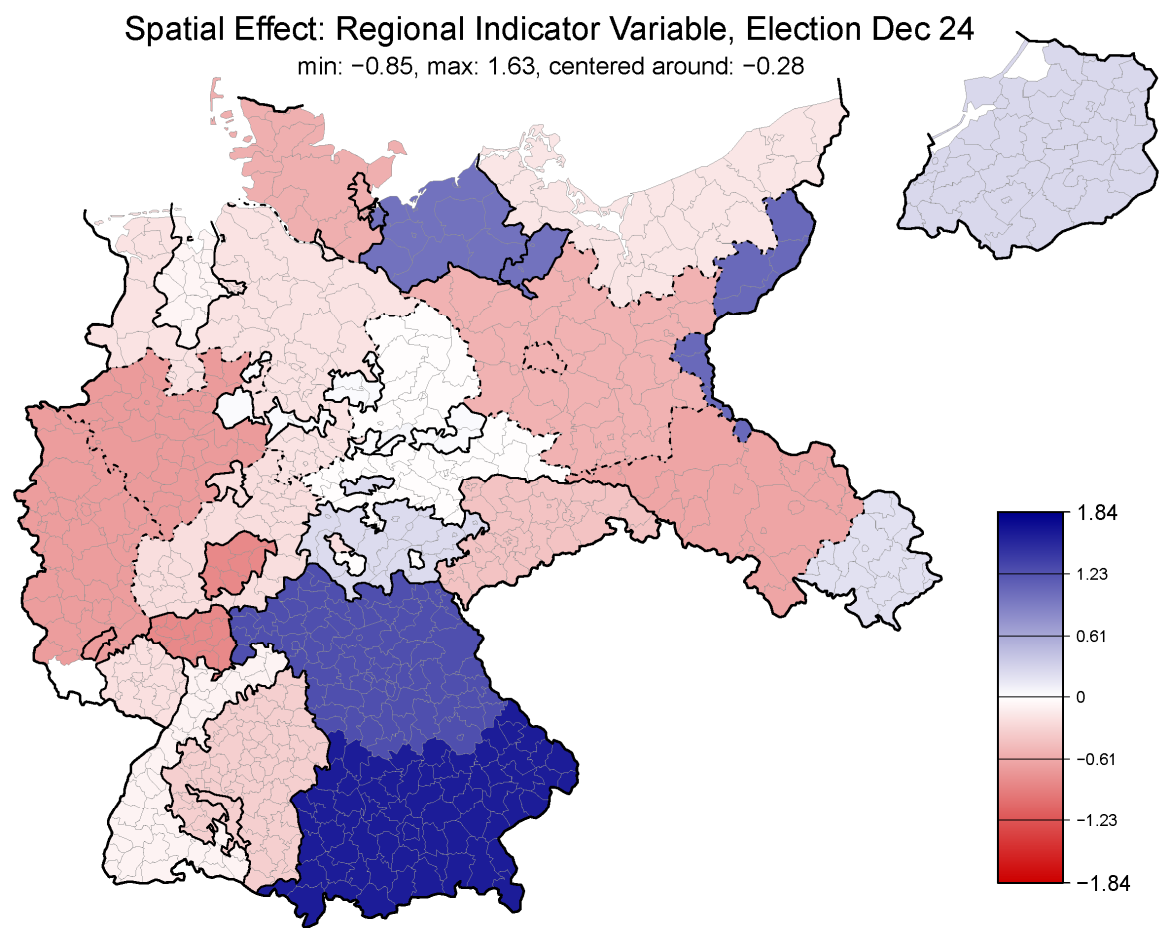

Figure 17: Regional Indicator Variable: Estimated Spatial Effect, Election December 1924, Centered Around Average Effect, Identical Scale Used for 1924 - 1928 Elections 
Spatial Effect: Regional Indicator Variable, Election May 28

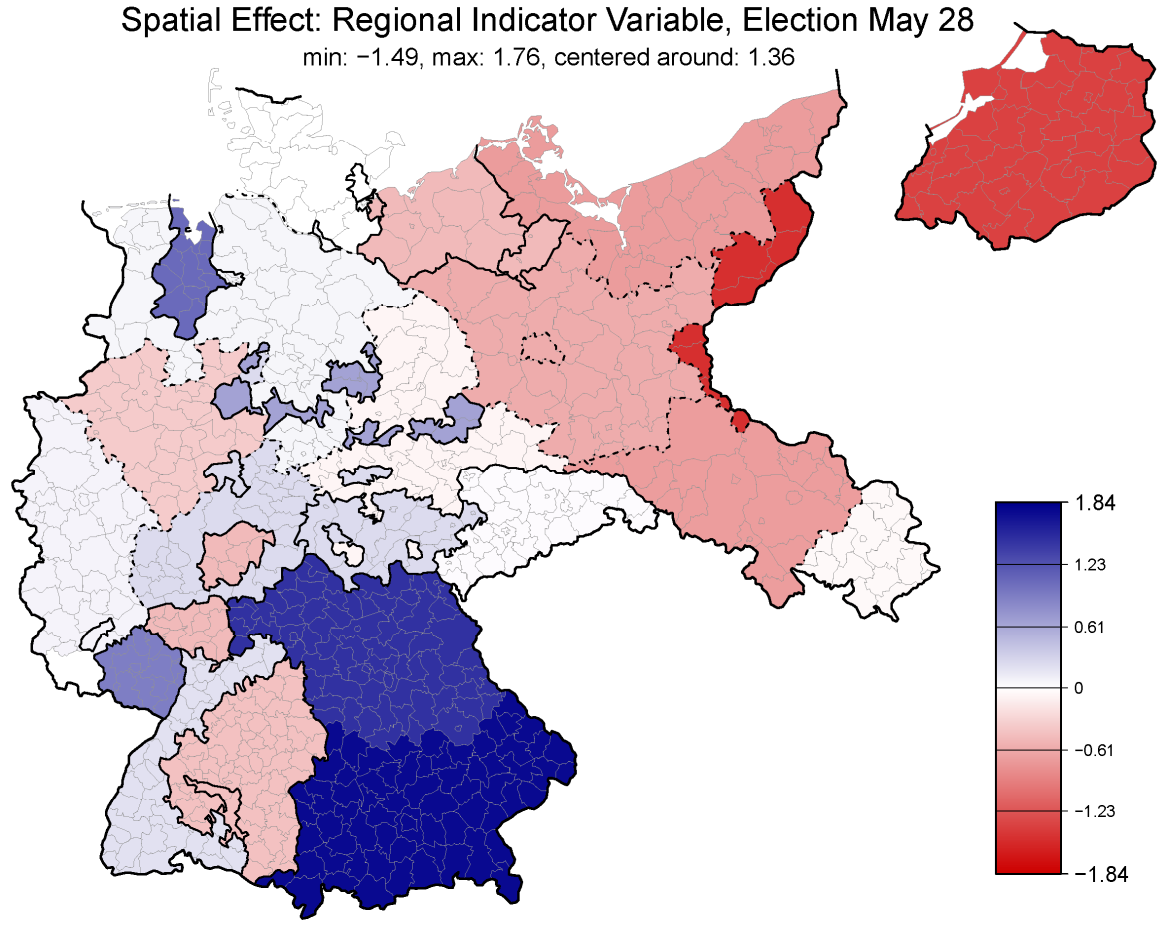

Figure 18: Regional Indicator Variable: Estimated Spatial Effect, Election May 1928, Centered Around Average Effect, Identical Scale Used for 1924 - 1928 Elections

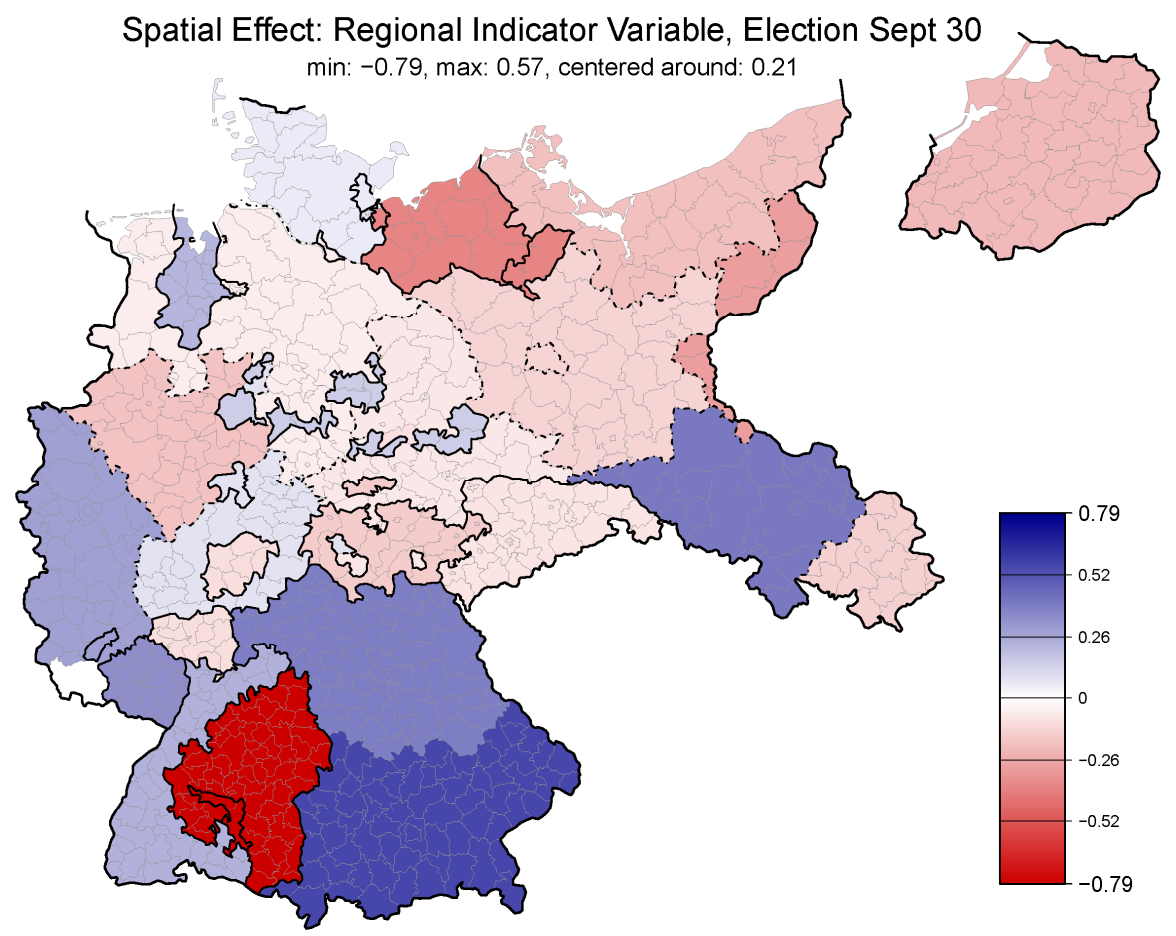

Figure 19: Regional Indicator Variable: Estimated Spatial Effect, Election September 1930, Centered Around Average Effect, Identical Scale Used for 1930 - 1933 Elections 
Spatial Effect: Regional Indicator Variable, Election Jul 32 min: -0.63 , max: 0.46 , centered around: 0.23

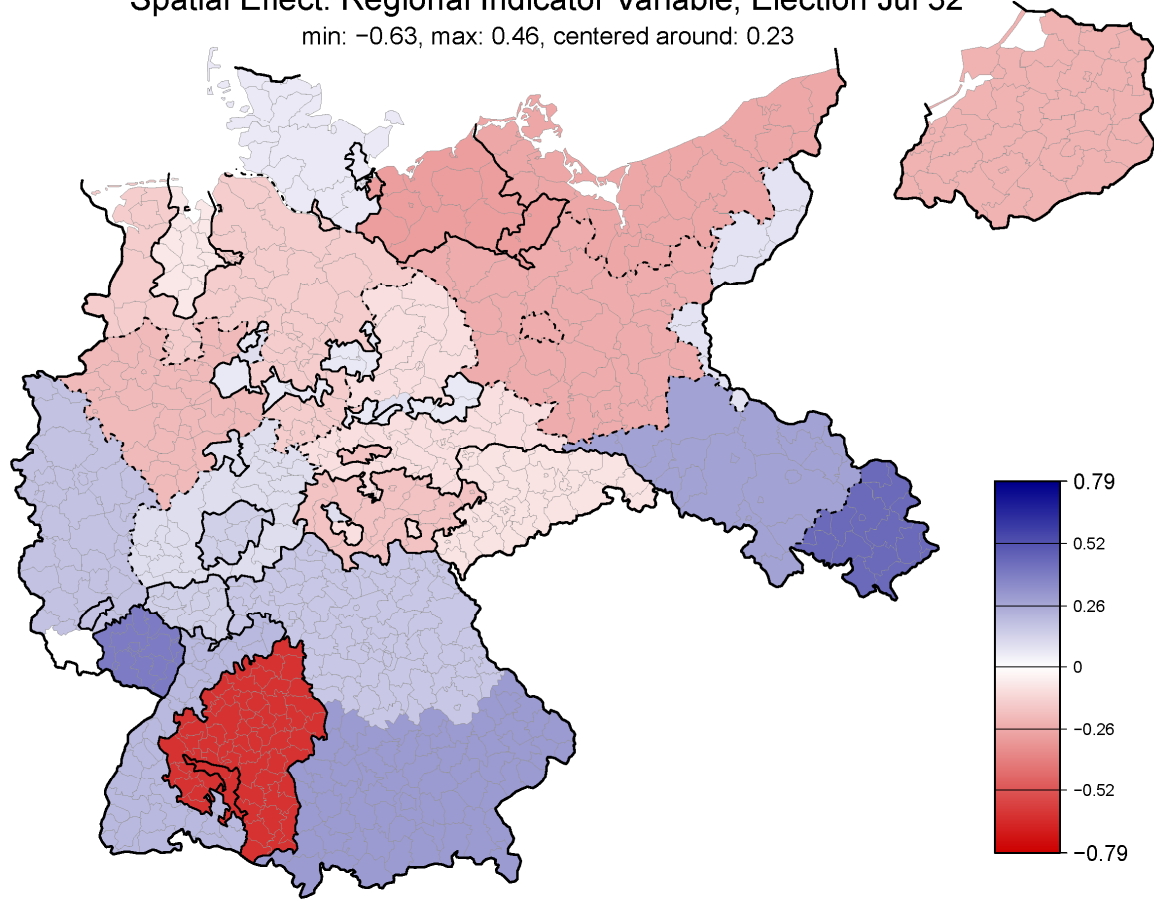

Figure 20: Regional Indicator Variable: Estimated Spatial Effect, Election July 1932, Centered Around Average Effect, Identical Scale Used for 1930 - 1933 Elections

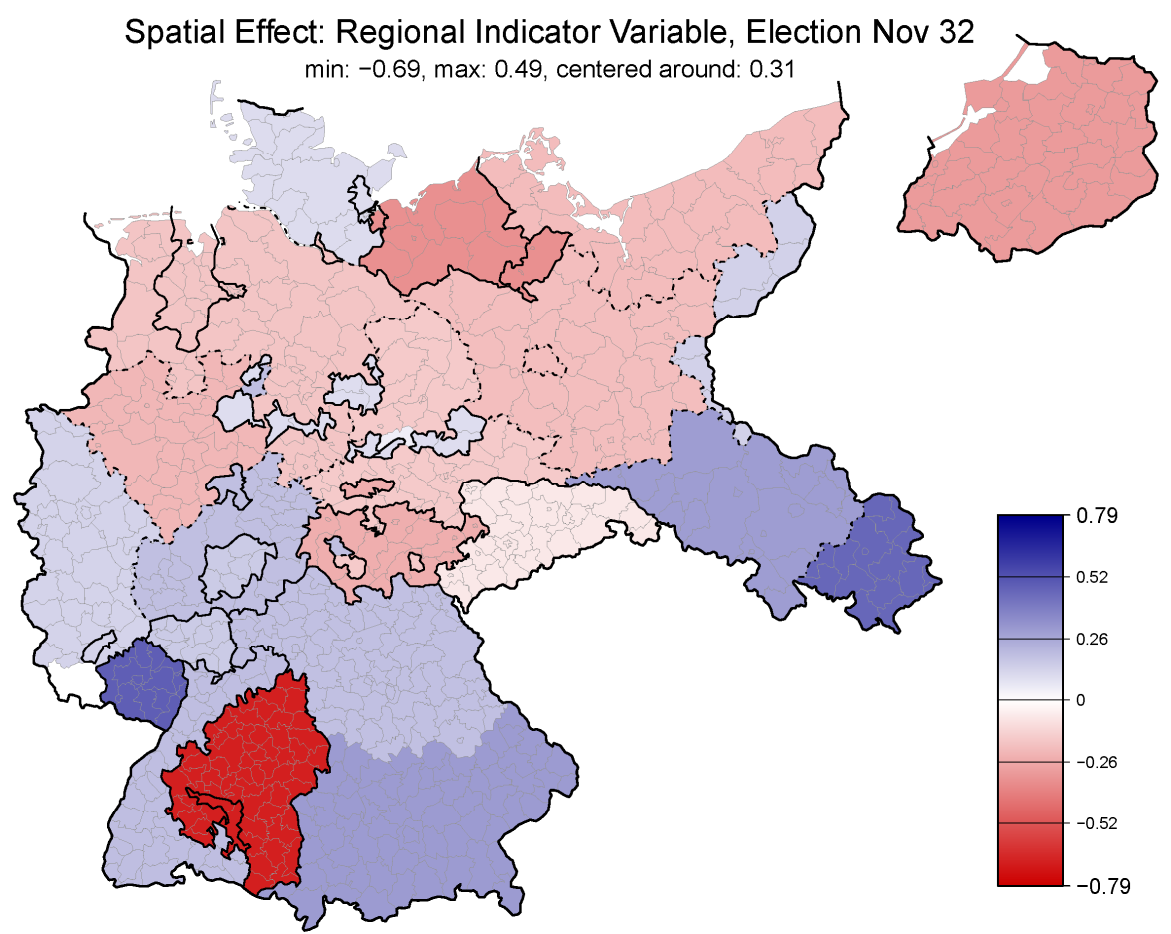

Figure 21: Regional Indicator Variable: Estimated Spatial Effect, Election November 1932, Centered Around Average Effect, Identical Scale Used for 1930 - 1933 Elections 
Spatial Effect: Regional Indicator Variable, Election Mar 33

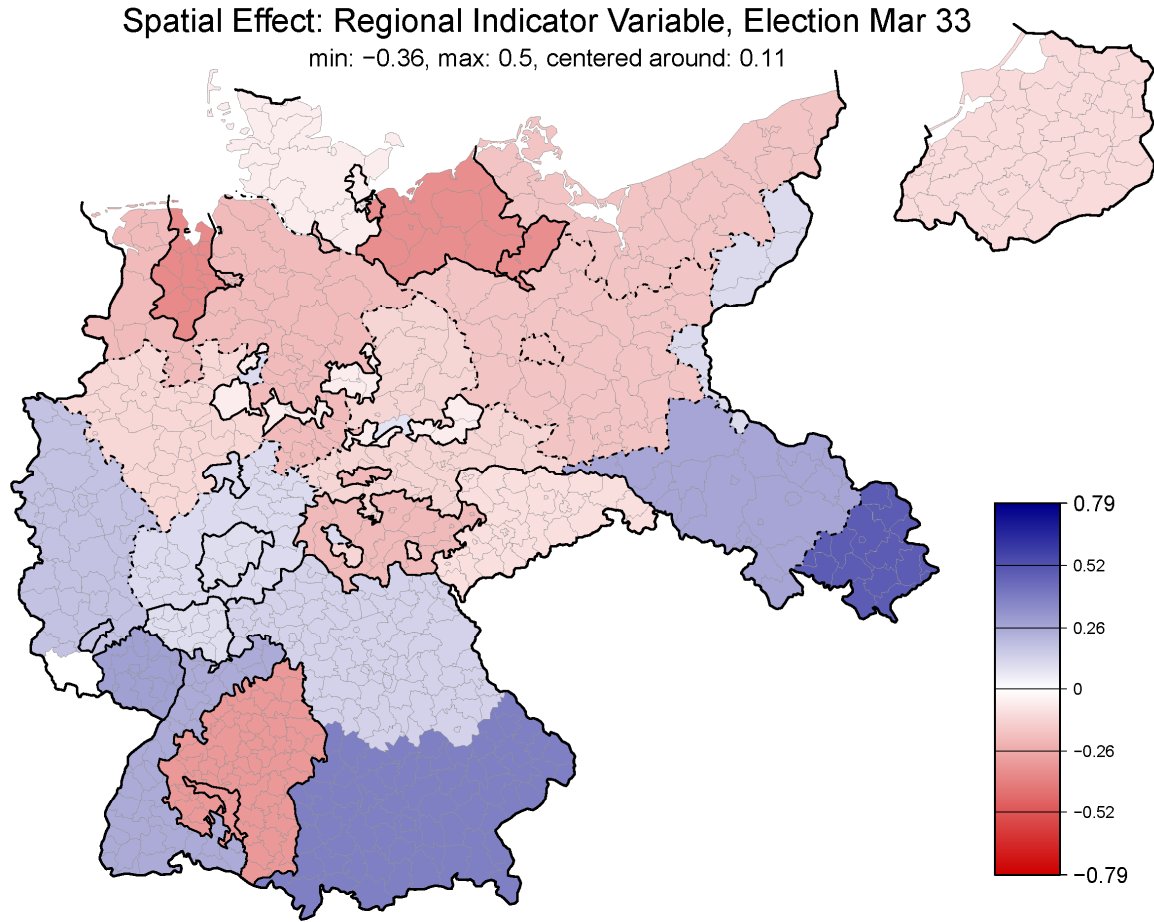

Figure 22: Regional Indicator Variable: Estimated Spatial Effect, Election March 1933, Centered Around Average Effect, Identical Scale Used for 1930 - 1933 Elections 

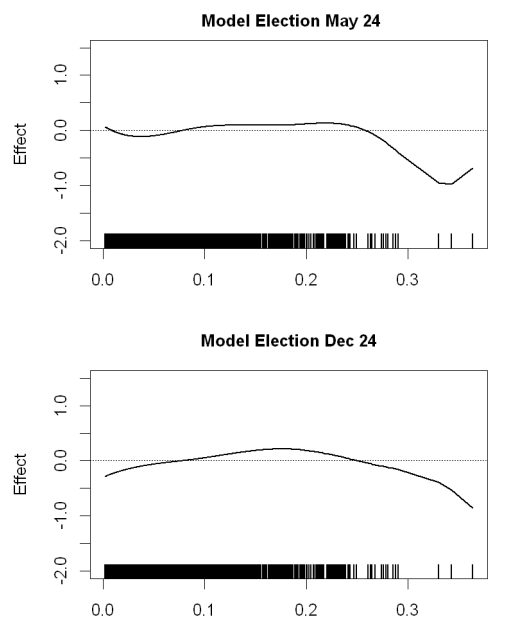

Model Election May 28

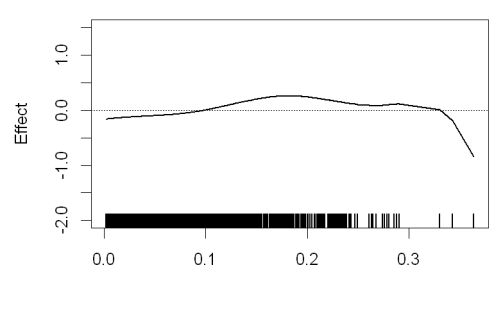

Model Election Sept 30

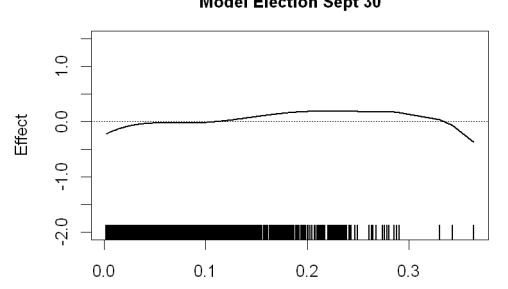

Model Election Jul 32
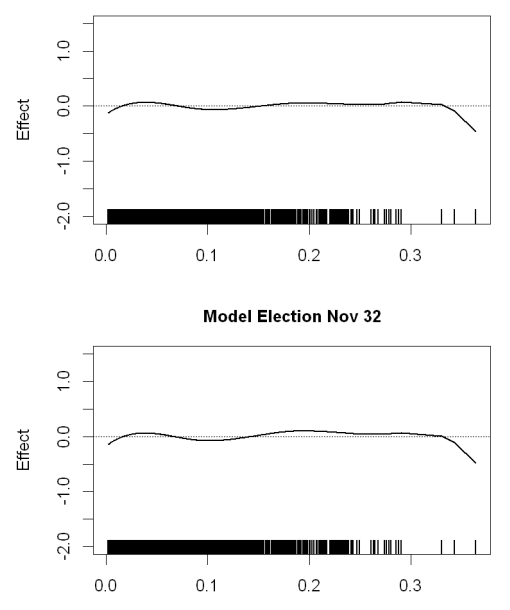

Model Election Mar 3

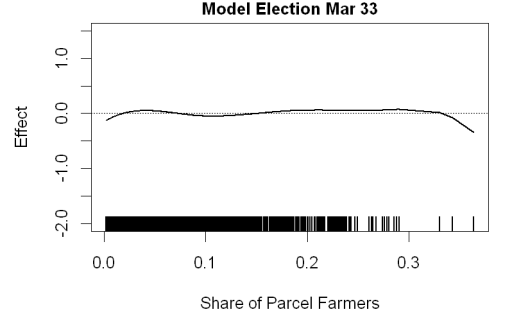

Model Election May 24

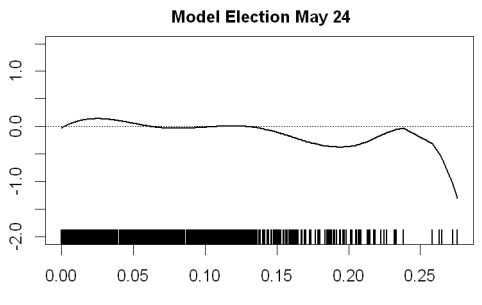

Model Election Dec 24

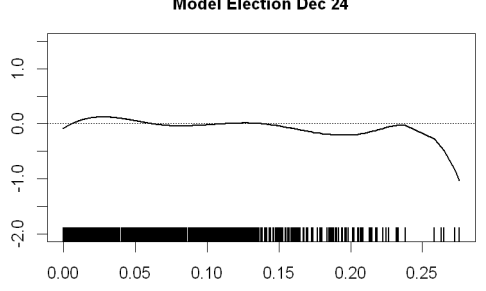

Model Election May 28
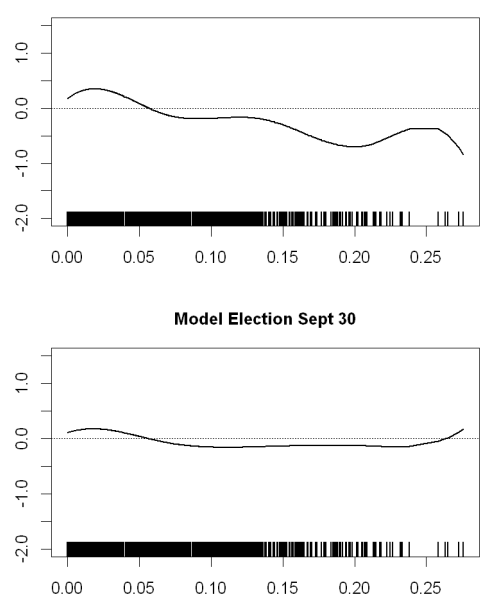

Model Election Jul 32
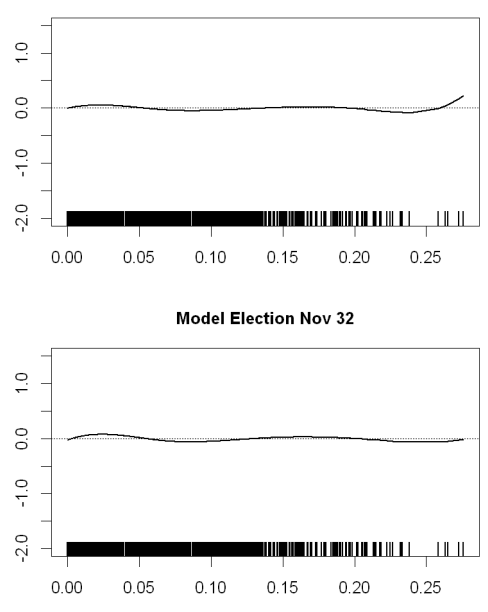

Model Election Mar 33

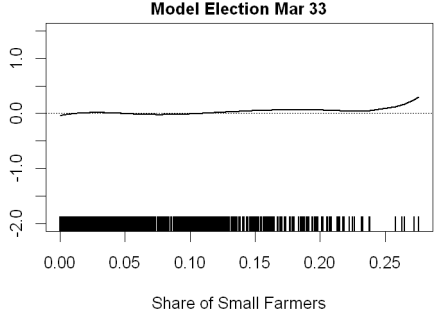

Model Election May 24

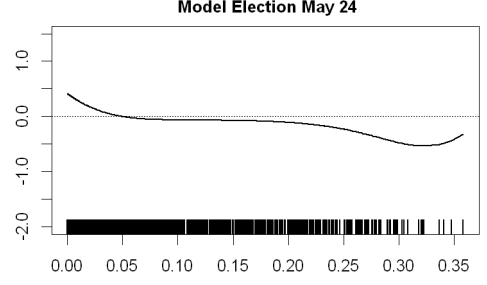

Model Election Dec 24

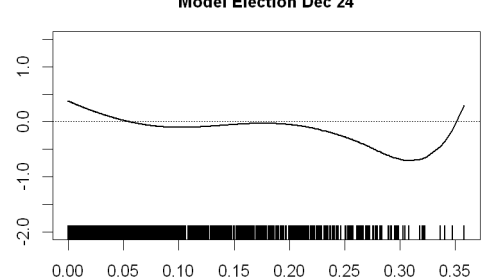

Model Election May 28

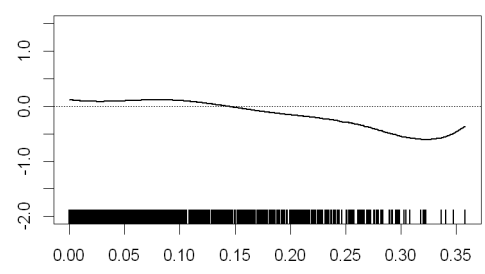

Model Election Sept 30

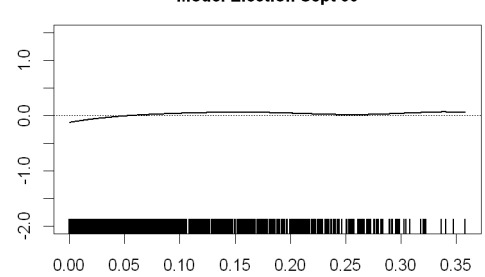

Model Election Jul 32

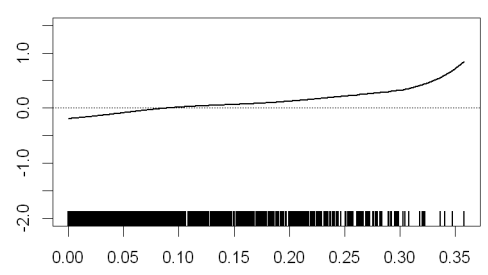

Model Election Nov 32

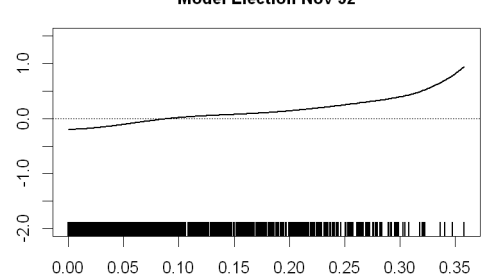

Model Election Mar 33

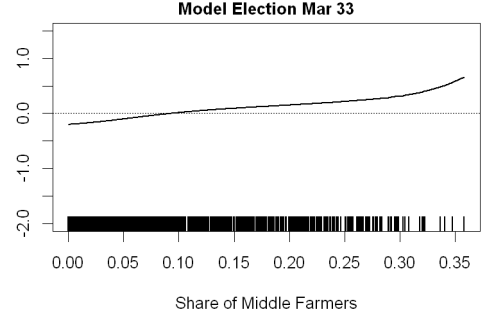

Figure 23: Effect for the Share of Parcel Farmer (0-2 ha), Share of Small Farmer (2-5 ha) and Share of Middle Farmer (5-20 ha) [columns], Elections May 1924 - March 1933 [rows] 

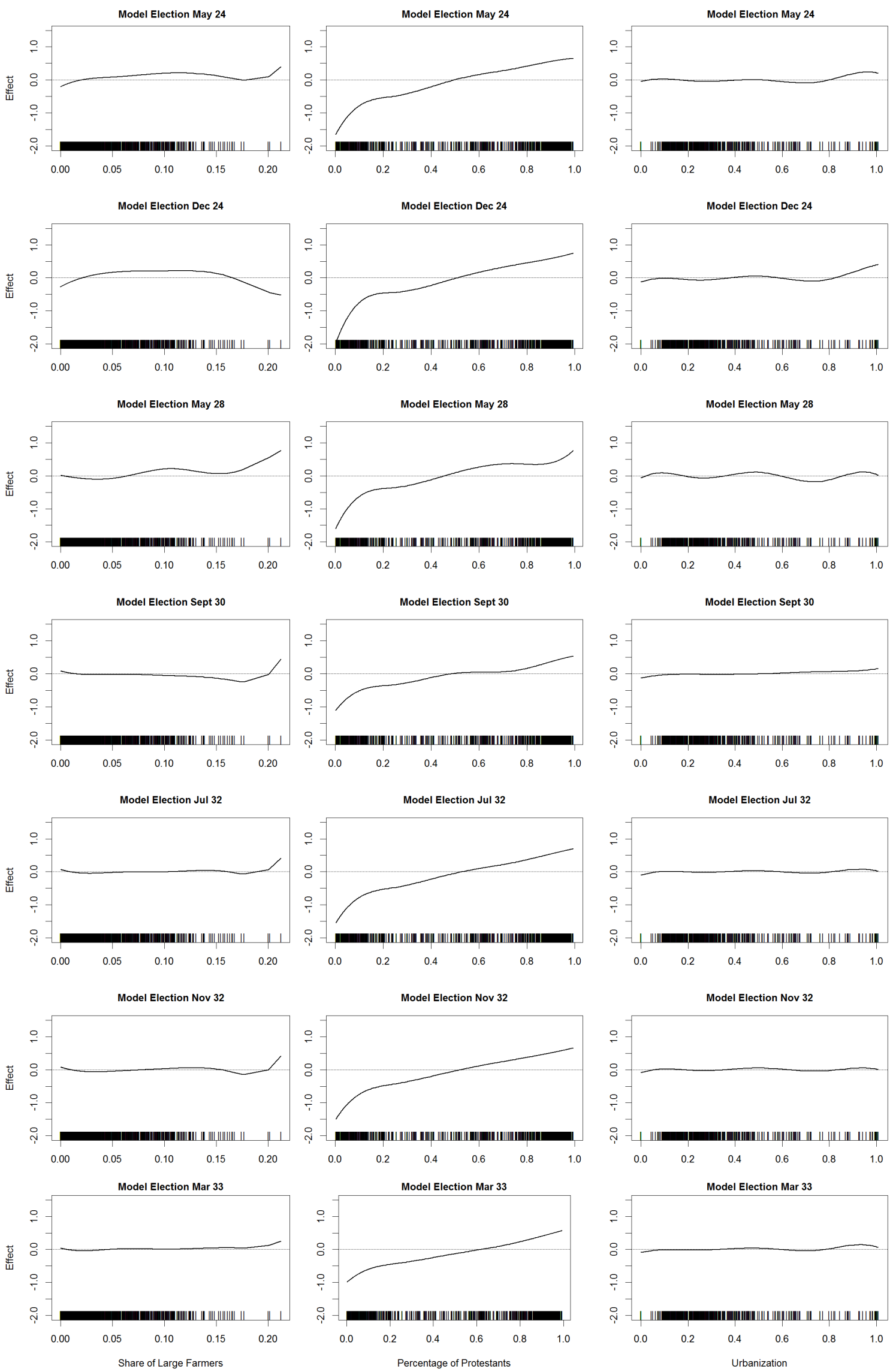

Figure 24: Estimated Smooth Effect of the Share of Large Farmer (20-100 ha), Percentage of Protestants and Urbanization [columns] on the Share of the NSDAP, Elections May 1924 - March 1933 [rows] 

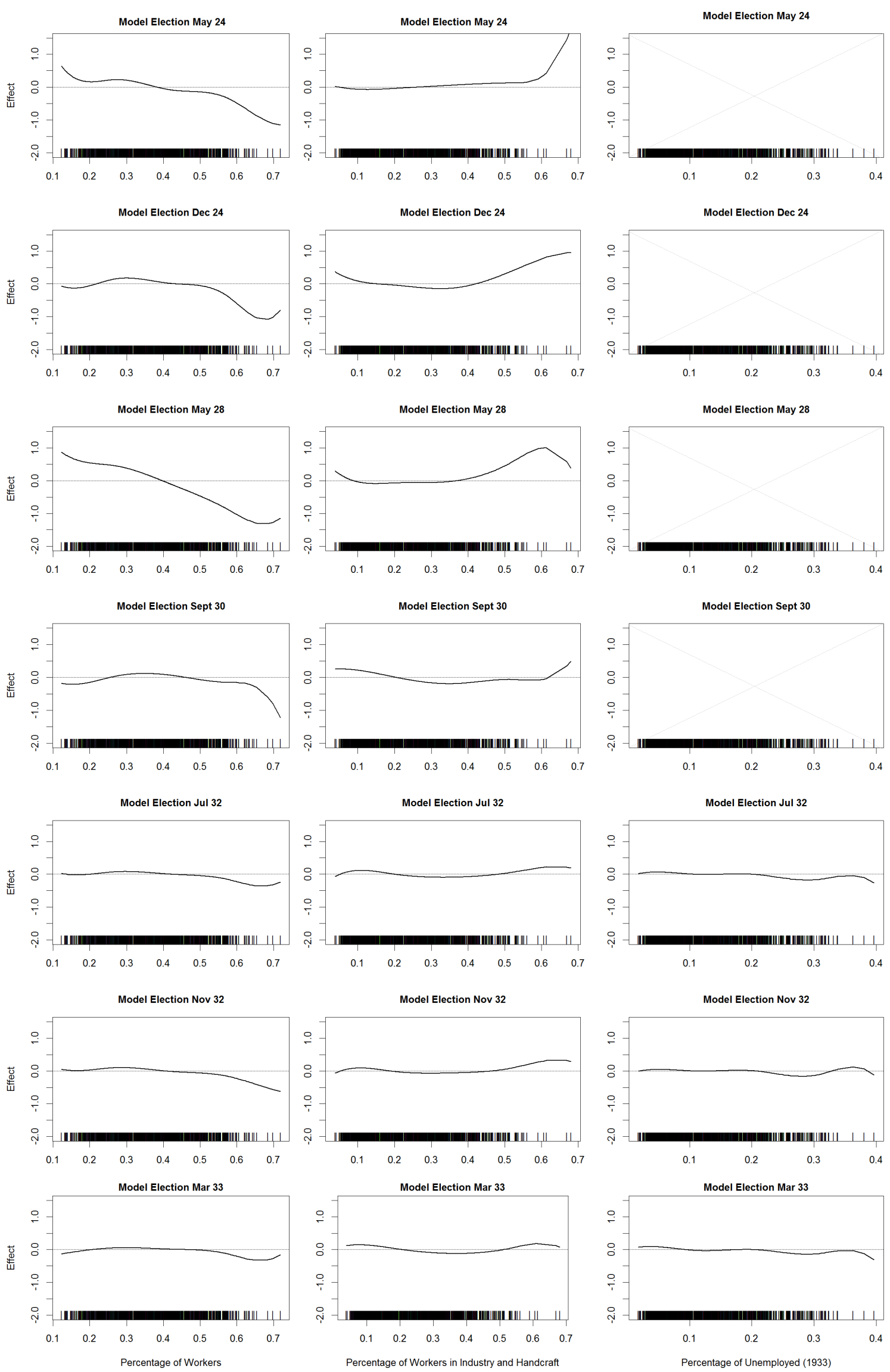

Figure 25: Estimated Smooth Effect of the Percentage of Workers, Percentage of Workers in Industry and Handcraft and Percentage of Unemployed (as at: 1933, only for 1932-33 Elections) [columns] on the Share of the NSDAP, Elections May 1924 - March 1933 [rows] 


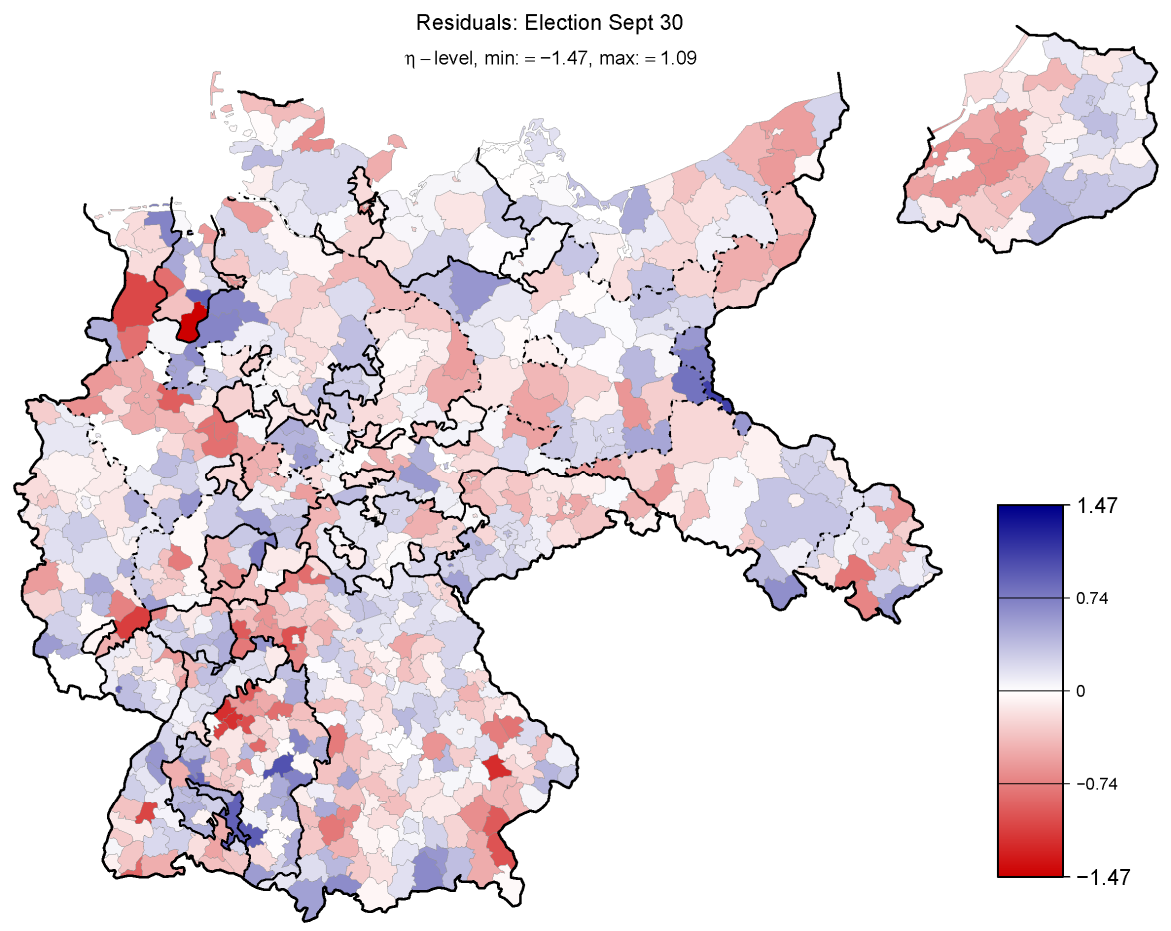

Figure 26: Residuals Model 1a, Election September 1930

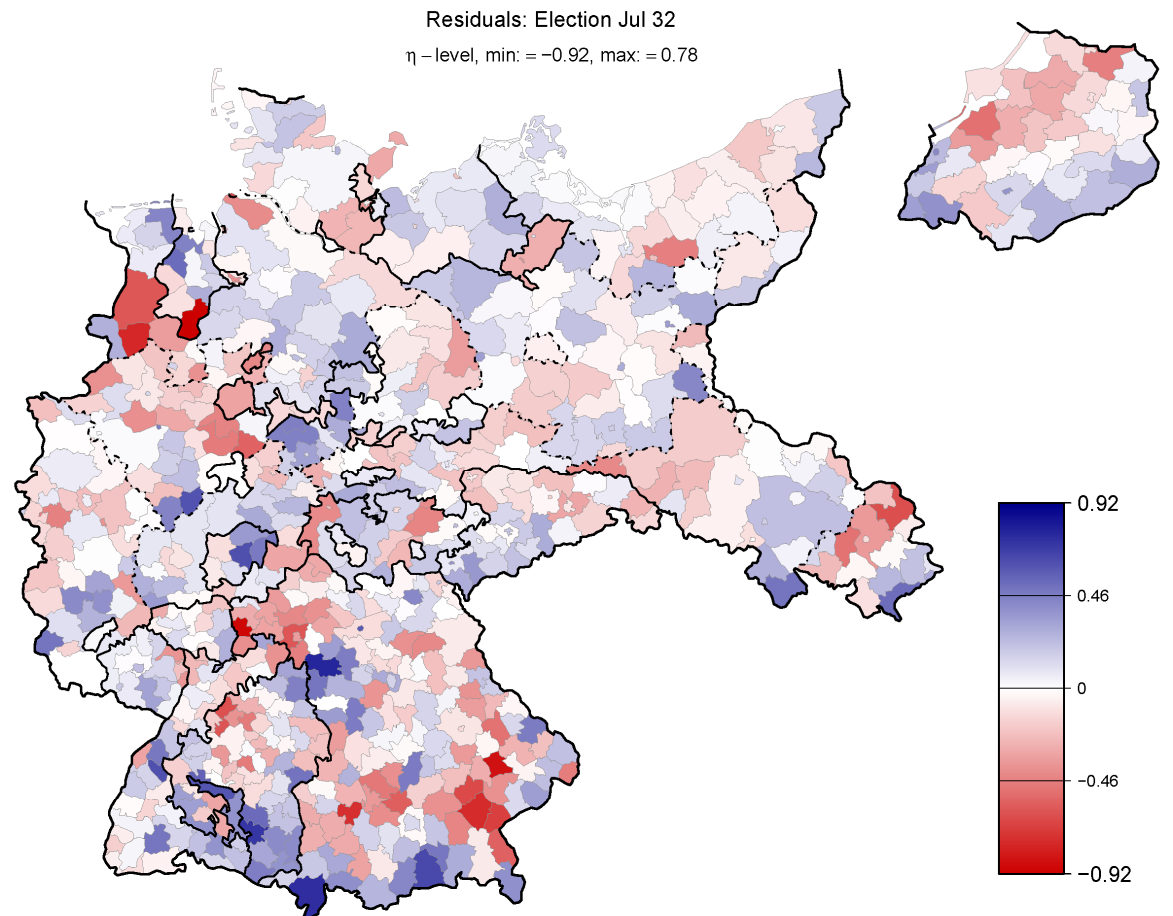

Figure 27: Residuals Model 1a, Election July 1932 


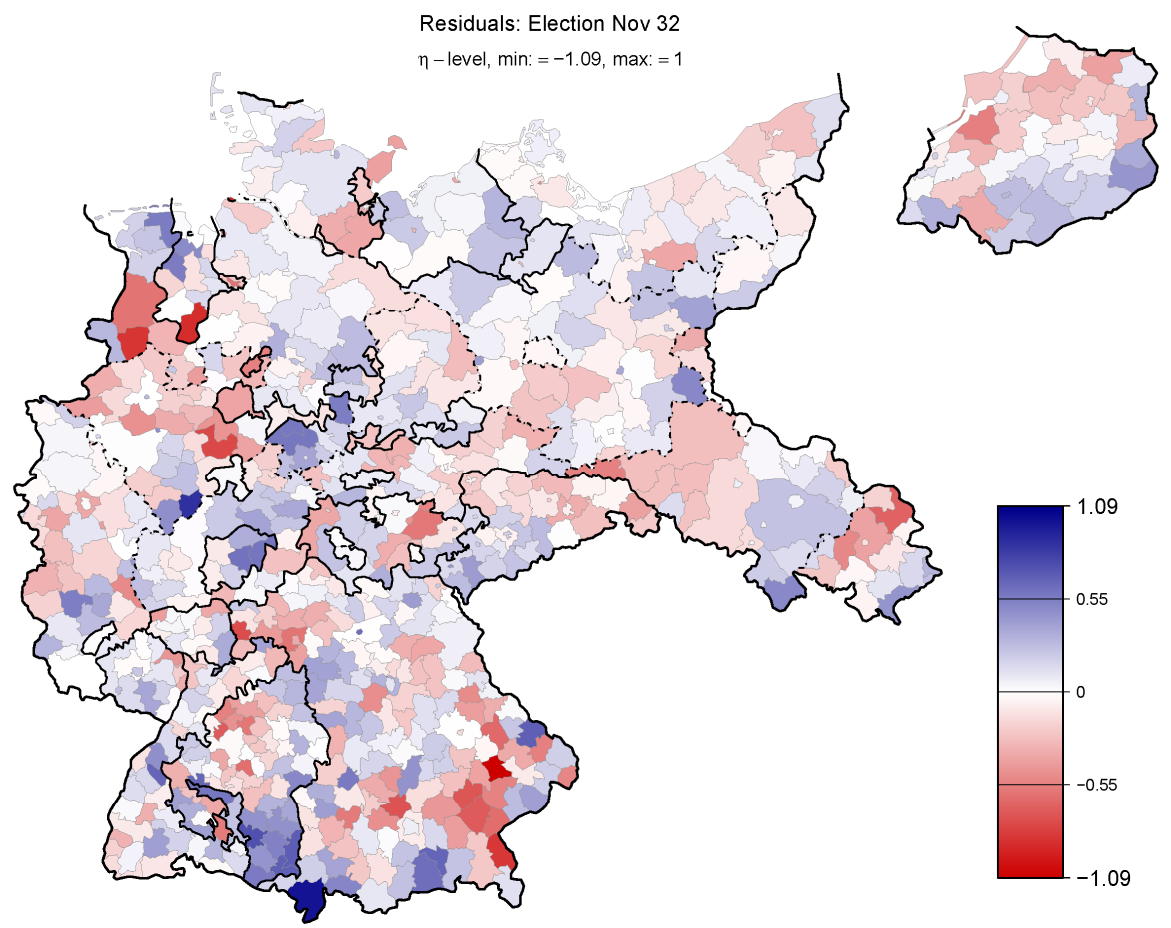

Figure 28: Residuals Model 1a, Election November 1932

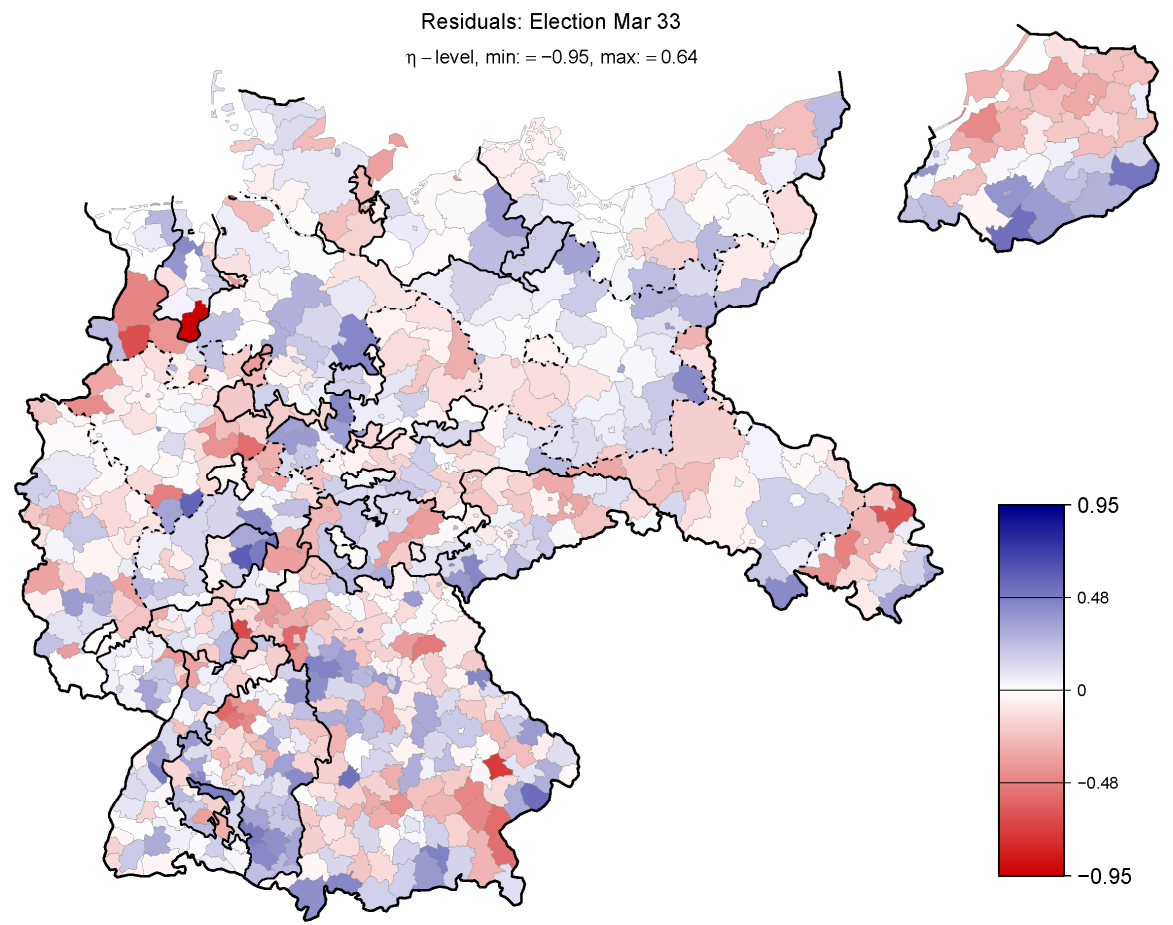

Figure 29: Residuals Model 1a, Election March 1933 